\title{
High pressure, quasi-isentropic compression experiments on the Omega laser
}

K.T. Lorenz, M.J. Edwards, A.F. Jankowski, S.M. Pollaine, R.F. Smith, B.A. Remington

June 12, 2006

Elsevier Journal, High Energy Density Physics 
This document was prepared as an account of work sponsored by an agency of the United States Government. Neither the United States Government nor the University of California nor any of their employees, makes any warranty, express or implied, or assumes any legal liability or responsibility for the accuracy, completeness, or usefulness of any information, apparatus, product, or process disclosed, or represents that its use would not infringe privately owned rights. Reference herein to any specific commercial product, process, or service by trade name, trademark, manufacturer, or otherwise, does not necessarily constitute or imply its endorsement, recommendation, or favoring by the United States Government or the University of California. The views and opinions of authors expressed herein do not necessarily state or reflect those of the United States Government or the University of California, and shall not be used for advertising or product endorsement purposes. 


\title{
High pressure, quasi-isentropic compression
}

\section{experiments on the Omega laser}

\author{
K.T. Lorenz, M.J. Edwards, A.F. Jankowski, S.M. Pollaine, R.F. Smith, B.A. Remington \\ Lawrence Livermore National Laboratory, Livermore, CA 94550 \\ For submission to the new Elsevier journal High Energy Density Physics \\ < http://www.elsevier.com/wps/find/journaldescription.cws_home/704940/description\#description>
}

(May 26, 2005, 8:20 am)

\begin{abstract}
The high energy density of pulsed lasers can be used to generate shockless loading in solids to high pressures and compressions but low temperatures. [Edwards, 2004] We have used the Omega laser to extend the capabilities of this technique to multiMbar pressures and compressions approaching a factor of 2 in aluminum foils. The energy from a $3.7 \mathrm{~ns}$ laser pulse is used to drive a strong shock through a $200 \mu \mathrm{m}$ polystyrene disc. The disc material unloads from a high-pressure state and expands across a $300 \mu \mathrm{m}$ vacuum gap where it stagnates against the sample to produce a smooth, monotonically increasing load with rise times from a few to $\sim 20$ ns. Ramped compression waves having peak pressures of 14-200 GPa (0.14-2.0 Mbar) and peak compressions $\rho / \rho_{0}$ of 1.1-2.0 were generated in the aluminum samples using laser pulse energies of $400 \mathrm{~J}$ to $2 \mathrm{~kJ}$. Wave profiles from a series of successively thicker targets loaded to $120 \mathrm{GPa}$ show the evolution of the high-pressure compression wave within the sample. The initial loading in the sample is shockless, and develops into a shock at a depth of $20-25 \mu \mathrm{m}$. We compare these wave profiles with hydrodynamic simulations from which we extract material temperatures and plastic strain rates behind the compression wave. Limitations and future prospects for this new shockless loading technique are discussed.
\end{abstract}




\section{INTRODUCTION}

High energy density (HED) conditions in matter can be created by heating samples to high temperatures, or at low to moderate temperatures, by compressing matter to high densities. The former can be achieved by heating a sample rapidly to high temperature $\mathrm{T}$, such as with a laser, or by driving a very strong shock through the sample. The latter conditions, namely, cool dense states of matter, apply to planetary interiors, for example, and have been experimentally more difficult to achieve. Creating pressures $\mathrm{P}>$ $100 \mathrm{GPa}$ (1 Mbar), which is required to compress solid density matter, without shocking (so as not to heat the sample) is experimentally challenging. Creating several $100 \mathrm{GPa}$, or even pressures $\mathrm{P}>1000 \mathrm{GPa}$ in a quasi-isentropic compression, which is relevant to planetary core conditions, [Guillot, 1999] has not yet been achieved in the laboratory. These conditions are interesting in their own right, since a plethora of phase transitions are predicted, as the lattice seeks to accommodate the state of high compression, as illustrated in Fig. 1 for aluminum. [Asay, 1997; Akahama, 2006; Moriarty, 1995; Boettger, 1996]

We show in Fig. 1 an illustrative P-T phase diagram for Al, [Young, 1991; Asay, 1997] superposed with the melt curve (upper dotted curve), the P-T path for the principal Hugoniot (heavy dotted curve), and also for a staged 3-shock loading (dot-dashed curve),

the P-T path for the room temperature isentrope (dashed curve), and a path representing a staged shock, off-Huginiot loading (dot-dashed curve). We are developing a quasiisentropic loading capability, with the goal of being close to the room-temperature isentrope, to be able to access very high pressure, low temperature regimes in the solid state. [Remington, 2005; 2006] Note, from Fig. 1 it is clear that multiple high-pressure phases of $\mathrm{Al}$, for example, will be accessible with such a loading path, but totally missed 
along the principle Hugoniot. It is hoped ultimately with the NIF laser, [Hogan, 2001] to be able to access new regimes of solid-state matter that have never before been observed in the laboratory.

There are several approaches for generating quasi-isentropic loading being pursued by various groups. A high energy-explosives (HE) approach was the first that we are aware of to show how quasi-isentropic, dynamic compression up to several x 100 kbar could be achieved. [Barnes, 1974; 1980] More recent quasi-isentropic work with this HE approach have achieved peak pressures over 700 kbar. [Raevsky, 2006] An approachg using graded density impactors on a gas gun is also being developed.

[Nguyen, 2004] An elegant approach using an increasing current to generate a magnetic pressure on the $\mathrm{Z}$ facility has led to quasi-isentropic compressions at peak pressures of $185 \mathrm{GPa}$, [Hayes, 2004] with hopes of pushing this yet peak pressure yet higher. The technique we are currently developing resembles the original HE approach of Barnes, except with the HE-initiated shock being replaced with a laser-driven shock to increase the energy density and hence, peak pressure. As will be described below, we have reached peak pressures of $200 \mathrm{GPa}$ with this quasi-isentropic drive, with hopes of increasing this by an order of magnitude to 1000-3000 GPa on NIF. [Remington, 2005; 2006] With these quasi-isentropic loading techniques being developed by multiple groups around the world, the ability to access and probe new regimes of solid state matter at e3xtreme pressures will be realized.

This paper is organized as follows. The experimental description and methodology is given in Sec. II, and in Sec. III we present our results. A discussion is given in Sec. IV, and we summarize in Sec. V. 


\section{EXPERIMENTAL DESCRIPTION}

In this section we describe our laser based experimental technique for reaching high pressures in a quasi-isentropic compression. Energy is deposited onto the front surface of a plastic reservoir, resulting in rapid heating and pressurization of the reservoir material. This launches a strong shock moving through the reservoir, effectively converting the laser energy into the necessary mass momentum for applying a load to the sample positioned "downstream" across a vacuum gap. When the shock reaches the gap, the reservoir material unloads nearly isentropically into vacuum and expands across the gap as a weakly ionized gas. The rapidly expanding reservoir material will then stagnate and accumulate against the sample, compressing it smoothly and monotonically in time, until the reservoir material is depleted.

To characterize the drive, the experimental package is an aluminum-LiF flat, as shown in Fig. 2. The spatially resolved particle velocity of the Al-LiF interface is measured as a function of time with a line VISAR (Velocity Interferometer for Any Reflector). [Celliers, 1998] These measurements provide a continuous, in-situ particle velocity record of the aluminum under dynamic loading conditions. Because the equation of state (EOS) of aluminum is well known up to pressures of a few Mbar [Knudson, 2005; Hayes, 2004; McQueen et al., 1970; Walsh, 1957; Mitchell, 1981; Nellis, 2003], the particle velocity records, $\mathrm{u}_{\mathrm{p}}(\mathrm{t})$, can be used to extract loading pressures, $\mathrm{P}(\mathrm{t})$, at the front of the samples. [Hayes, 2001a; 2004] Details on the conversion of the VISAR records to pressure histories are given below. 
The targets, shown in Fig. 2, consist of a reservoir and an Al-LiF target package separated by a precision spacer. Reservoirs consisted of a $28 \mu \mathrm{m}$ thick polyimide ablator $\left(\mathrm{C}_{22} \mathrm{H}_{10} \mathrm{~N}_{2} \mathrm{O}_{5}\right.$, density $\left.\rho=1.42 \mathrm{~g} / \mathrm{cm}^{3}\right)$ glued to a $170 \mu \mathrm{m}$ thick layer of $12.5 \%$ brominated polystyrene $\left(\mathrm{C}_{8} \mathrm{H}_{6} \mathrm{Br}_{2}\right.$, density $\left.\rho=2.00 \mathrm{~g} / \mathrm{cm}^{3}\right)$. The bromine dopant functions as a preheat shield by absorbing x-rays formed in the laser ablation region at the front of the target. In addition, the dopant increases the average density of the reservoir material, resulting in a softer loading rate in the sample [Edwards, 2004]. The polyimide serves as the laser ablation material. The ablation layer should have components of low atomic number in order to avoid generating hard x-rays, which could pre-heat or melt the front surface of the sample before the loading process begins. The reservoir was glued to a $5 \mathrm{~mm}$ outer diameter polystyrene spacer precision milled to a thickness of $300 \mu \mathrm{m}$, and bored to an inner diameter of $2 \mathrm{~mm}$. A slot was milled into the spacer for evacuation of the air in the gap behind the reservoir. Dimensional variations between targets, such as reservoir thickness and gap length, were typically less than $5 \%$.

The target package consisted of 5-35 $\mu \mathrm{m}$ of aluminum, vapor deposited [Jankowski, 2004; 2005] onto a $125 \mu \mathrm{m}$ thick LiF optical flat window. The LiF functions as a stable mount for the relatively thin aluminum deposition layers, and as a transparent window for making the in situ particle velocity measurements of the Al-LiF interface. Evaporative coatings eliminate the need for a glue layer between the sample and the window. In addition, the LiF is very nearly impedance matched to the aluminum. These two factors reduce the wave reflections at the $\mathrm{Al}-\mathrm{LiF}$ interface, which can complicate analysis and interpretation of the VISAR data. The aluminum samples were deposited over a temperature range of $230-250{ }^{\circ} \mathrm{C}$ and at rates of $21-25 \mathrm{~nm} / \mathrm{s}$ using an electron-beam 
evaporation source and $99.999 \%$ pure aluminum. Under these deposition conditions the $\mathrm{Al}$ is measured as fully dense $\left(2.70 \mathrm{~g} / \mathrm{cm}^{3}\right)$ and has a textured polycrystalline microstructure. Typically, the grain size for these samples is a few microns in the asdeposited condition. X-ray diffraction in the $\theta / 2 \theta$ mode indicates that the aluminum samples are oriented with the (111) axis normal to the deposition plane, which is along the direction of loading, but are randomly oriented (ie, polycrystalline) in the transverse direction. Profilometry measurements determined the aluminum thickness to $10.3 \pm 0.4$ $\mu \mathrm{m}$ for most of the targets used in this study. A second set of shots to investigate the shape of the evolving wave as a function of depth, $\mathrm{z}$, into the sample used targets with aluminum coatings that varied from $5 \mu \mathrm{m}$ to $\sim 35 \mu \mathrm{m}$.

A line VISAR system [Celliers, 1998] was used in this study for measuring $u_{p}(x, t)$ as a function of position, $\mathrm{x}$, and time, $\mathrm{t}$, on the Al-LiF interface. The VISAR determines the phase shift of the light reflected from the moving surface at the back of the target by measuring the phase difference between two parts of the reflected waveform separated by a known time delay. The probe source for this VISAR system was an injection seeded Qswitched YAG laser operating at a wavelength of $532 \mathrm{~nm}$ with a stretched pulse of $\sim 25 \mathrm{~ns}$ (FWHM). The Omega VISAR system consists of two independent interferometer legs, to provide a range of temporal and velocity sensitivities. Streak cameras were used to time resolve the output image from the interferometers. A slit aperture on the streak camera provides spatial discrimination. The spatial field of view for the two VISAR systems used here was approximately $550 \mu \mathrm{m}$ and $700 \mu \mathrm{m}$. (Differences between these two field-ofviews were due to differences in the relay lengths between optics.) The spatial resolution was $\sim 10 \mu \mathrm{m}$ for both systems. Temporal discrimination in the interferometer legs is 
handled by streak cameras that rapidly sweep the interferometer image from the slit across a CCD detector. The signal was digitized using a 1536 (temporal direction) $\times 1024$ (spatial direction) 16-bit CCD. For this study, the streak cameras used sweep rates of 8.3 and 29 ps/pixel. These rates provided coverage of $\sim 10 \mathrm{~ns}$ and $30 \mathrm{~ns}$ of target dynamics.

The velocity sensitivity of the system is set by the transit delay of the light as it passes through an etalon of known thickness, given by

$$
\tau=\frac{2 d}{c}\left(n-\frac{1}{n}\right)
$$

where $d$ is the etalon thickness, $c$ is the speed of light, and $n=1.4607$ is the index of refraction of the etalon material (fused silica) at $532.0 \mathrm{~nm}$. Etalon delays of 37.3, 63.1 and 157 ps were used in this study. For measurement of a surface-vacuum interface the velocity sensitivity is

$$
V P F_{0}=\frac{\lambda}{2 \tau(1+\delta)}
$$

where $\mathrm{VPF}_{0}$ is the velocity change per fringe shift taken from the interferometer record, $\lambda$ $=532 \mathrm{~nm}$ is the wavelength of the VISAR probe laser, $\tau$ is the etalon delay given in Eq. 1 , and $\delta=0.0318$ is a correction for the dispersion in the etalon. [Celliers, 2004] Etalon delays listed above correspond to velocity sensitivities of $6.91,4.08$ and $1.65 \mathrm{~km} / \mathrm{s}$ per fringe. For measurements of surface velocities viewed through transparent windows, an additional correction factor must be applied. This factor depends on how the window's 
index of refraction changes with compression due to the passage of the high-pressure loading wave. The VPF for this arrangement is simply

$$
V P F_{w}=V P F_{0}\left(1+\frac{\Delta v}{v_{0}}\right)^{-1},
$$

where $\Delta v / v_{0}$ corresponds to the fractional velocity correction for the index of refraction change between the unshocked and shocked window. The correction factor for $\mathrm{LiF}$ windows has been measured [Wise, 1986] for pressures up to $115 \mathrm{GPa}$. Values for $\Delta v / v_{0}$ are constant to less than $3 \%$ with an average value of 0.281 . This work used this average value to correct all window measurements up to a peak pressure of $200 \mathrm{GPa}$.

The temporal resolution of the system is limited by the impulse response of the streak camera ( $\sim .5 \%$ of the sweep window) and the transit time of the probe light through the interferometer delay etalon. The temporal resolution in the "fast sweep" leg ( $\sim 10 \mathrm{~ns}$ window) is limited by the etalon transit time of $157 \mathrm{ps.} \mathrm{The} \mathrm{"slow} \mathrm{sweep"} \mathrm{(} 30$ ns window) temporal resolution was limited by the $\sim 230 \mathrm{ps}$ impulse response of the streak camera.

The laser drive consisted of ten beams (wavelength, $\lambda_{\mathrm{L}}=351 \mathrm{~nm}$ ), symmetrically oriented about the target axis. Six beams were inclined at $48^{\circ}$ and four at $23^{\circ}$ from the target normal. The temporal pulse shape was a $3.7 \mathrm{~ns}$ square pulse with $\sim 100 \mathrm{ps}$ rising and falling edges. All beams were co-timed and delivered equivalent power to within $10 \%$. Beams used distributed phase plates (DPP) for spatial smoothing and shaping [Boehly, 1997]. The on-target spatial intensity distribution for a single beam at normal incidence can be modeled with a super-Gaussian radial intensity profile, 


$$
I(r)=I_{0} e^{-\left(\frac{r}{450 \mu m}\right)^{5}}
$$

The spatial intensity variations in the flat portion of the profile were less than $10 \%$.

\section{RESULTS}

Results from two different shot series are presented here. The first series of five shots examines how sample loading scales with laser intensity. All other aspects of target geometry, sample characteristics and laser parameters (such as pulse length) are held constant. It will be shown that the pressure in the sample scales linearly with the laser intensity, up to a maximum pressure of $200 \mathrm{GPa}$, limited by the energy of the laser available for planar illumination. The loading rate in the shock-free regime increases with laser intensity, leading to rise times $<10 \mathrm{~ns}$ for peak loads above $100 \mathrm{GPa}$. A second series of shots demonstrates that, even at these very high pressures and loading rates, the initial loading in the samples is shockless. Particle velocities are measured for four targets having progressively thicker samples. The evolution of the compression wave as it steepens into a shock is demonstrated for aluminum loaded to $120 \mathrm{GPa}$.

\section{A. The Loading Dependence on Laser Intensity}

A VISAR record for the highest laser intensity shot is shown in Fig. 3a. The laser intensity for this shot was $7.9 \times 10^{13} \mathrm{~W} / \mathrm{cm}^{2}$ and corresponds to a peak load in the sample of $200 \mathrm{GPa}$. The image in Fig. 3a is a $500 \times 550$ pixel cutout of the original $1536 \times 1024$ 
pixel VISAR record. The horizontal axis of the image is the camera's "streak" or time direction, while the vertical axis corresponds to the transverse position along the back of the sample. The interference fringes of the velocity interferometer record show the motion of the reflective rear surface of the $\mathrm{Al}$ sample at the $\mathrm{Al}-\mathrm{LiF}$ interface. In this case, the VISAR measures the particle velocity, as a function of time and position on the sample, of the compression wave as it passes from the aluminum into the $\mathrm{LiF}$ window. The change in velocity is directly proportional to a known velocity per fringe shift calibration set by the thickness of the etalon used in the VISAR diagnostic. The velocity sensitivity, $\mathrm{VPF}_{\mathrm{w}}$, as defined in Eq. (3), for this record was $5.46 \mathrm{~km} / \mathrm{s}$ per fringe. The initial upward deflection of the fringes represents the positive velocity change of the leading edge of the compression wave, and the longer trailing downward deflection shows the negative velocity change associated with the falling pressure as the wave passes. The fringe motion is smooth and continuous throughout the entire loading and release portion of the wave.

The velocity interferogram shown in Fig. 3a was reduced to a velocity-time record using a Fourier transform methodology, which has been described in detail elsewhere [Celliers, 2004]. This analysis includes the corrections for dispersion in the etalons and window effects, as described by Eqs. (2) and (3). Corrections for non-normal incidence of the VISAR probe light, due to the use of a relatively fast focusing optic (F/3.3), are less than $1 \%$ and have not been implemented in our analysis [Celliers, 2004]. Figure $3 \mathrm{~b}$ shows the time-dependent particle velocity and pressure profiles extracted from the VISAR record shown in Fig. 3a. The lower trace shows the velocity of the Al-LiF interface. The rise time for the loading wave is $\sim 4 \mathrm{~ns}$, and is well resolved in both 
interferometer records. The solid line represents the average velocity over a $300 \mu \mathrm{m}$ target region. In order to quantify the planarity of the loading, the same analysis was carried out over six $50 \mu \mathrm{m}$ wide sub-regions distributed laterally across the sample. The velocity deviations are represented by the gray zone bounding the solid trace, which represents the $90 \%$ confidence limit. The average deviation in the peak particle velocity over this $300 \mu \mathrm{m}$ region is $\sim 3.6 \%$ and is attributed mainly to laser speckle in the VISAR image, rather than planarity deviations in the loading.

It has been recently suggested that additional corrections may be necessary when a non-steady wave propagates through the LiF window [Hayes, 2004]. The evolving wave ramps into a shock, and undergoes subsequent attenuation. This non-steady condition adds additional complexities that can affect how accurately one can extract the Al-LiF interface velocity. Forward simulations indicated that the window effects caused an over-estimate of the pressure by $\sim 8 \%$, for a peak load of 200GPa.

The loading history at the front surface of the sample can be extracted by a "backintegration" technique, if the equation of state (EOS) and thickness of the sample are known.' [Hayes, 2001] The EOS of aluminum is well known to pressures approaching $300 \mathrm{GPa}$. [Nellis, 2003] The technique implements a "back-integration" technique that uses the experimental particle velocity to determine the pressure loading history at the front face of the sample. The standard Euler equations were integrated backward in space using the particle velocity data at the Al-LiF interface as the initial condition. The method assumes isentropic loading and is not valid for data with shock discontinuities. The resulting pressure profiles are shown alongside the particle velocity data in Fig. 3b. Error bands from the particle velocity results have been passed through the analysis to 
determine the spatial deviations in loading across the sample, and are shown in gray, representing an average pressure deviation of $\sim 5.5 \%$ at the peak of the drive. As an initial check on the assumption that the loading is isentropic, the pressure profiles extracted from the back-integration technique (which assumes isentropic compression) were forward propagated through the sample using the CALE hydrodynamic package (which does not assume isentropic loading). [Barton, 1985] The resulting simulated particle velocity reproduced the experimental particle velocity very well. More will be said on this point in the next section.

A series of nearly identical targets were shot over a wide range of laser intensities in order to determine how the maximum pressure and loading rise time scale with the laser intensity for this type of drive. Targets were loaded at laser intensities covering nearly an order of magnitude. Peak loads of $14 \mathrm{GPa}$ (curve e, Fig. 4) were achieved at a laser intensity $\sim 8.2 \times 10^{12} \mathrm{~W} / \mathrm{cm}^{2}$, while the $200 \mathrm{GPa}$ load (curve a, Fig. 4) required an intensity of $7.9 \times 10^{13} \mathrm{~W} / \mathrm{cm}^{2}$. Figure 4 shows the reduced pressure-time loading histories for this series, and the shot details corresponding to these curves are given at the top of Table 1. Again, the time axis is relative to the time when the leading edge of the laser pulse is incident on the front surface of the reservoir. The low-pressure curve e represents a target having a lower density reservoir of $1.2 \mathrm{~g} / \mathrm{cm}^{3}$ (compared to $2 \mathrm{~g} / \mathrm{cm}^{3}$ ) due to a lower concentration of bromine ( 2 at. \%) in the brominated polystyrene. This target had identical dimensions as the other targets in the series. The data from this target shot was reported previously [Edwards, 2004] but is included here to show the full range of the pressure scaling achieved to date with solid density reservoirs. Several features are apparent in the data. The peak pressure in the sample increases with increasing laser 
intensity. However, the loading rate also increases and the onset of loading moves earlier in time. The $200 \mathrm{GPa}$ shot reaches peak pressure in $\sim 4-5 \mathrm{~ns}$, while the shots below $\sim 50$ GPa achieve peak loading in 10-20 ns. The rate of loading and the detailed loading profile are determined by the density-velocity distribution of the unloading reservoir. The ablation pressure at the front of the reservoir scales with the laser intensity as, $\mathrm{P}_{\text {reservoir }} \sim$ $I_{\text {laser }}^{0.76}$. [Edwards, 2004; Remington, 2004] The higher laser intensities generate higher shock speeds in the reservoir, giving rise to earlier unloading of the reservoir material into the vacuum gap. The higher laser intensities also give rise to higher peak velocities for the material sweeping across the gap. These two effects explain the more rapid onset of loading as a function of laser intensity. The pressure in the sample at any time is equal to the ram pressure of the unloading vapor, $P_{\text {ram }} \sim \rho_{\text {gas }} u_{\text {gas }}^{2}$, where $u_{\text {gas }}$ is the velocity of the inflowing reservoir plasma at density $\rho_{\text {gas }}$ incident on the sample. Higher unloading velocities and densities lead to higher peak pressures in the sample.

The low-pressure end ( $<10 \mathrm{GPa})$ of this drive has not yet been explored. Lowpressure loads can be imparted to the sample by decreasing the laser intensity, but a point will be reached where the reservoir material will not unload properly into the gap. In this situation the laser intensity must be above some critical value where the reservoir material will unload from the shocked state to a point above the material's vapor-liquid boundary. The simplest way to ensure low-pressure, shock-free loading is to increase the length of the vacuum gap up to the point where release waves from the side begin to introduce $2 \mathrm{D}$ effects. This point can be approximated using the diameter of the laser drive spot. Thus, the total target thickness should not be greater than the diameter of the flat central diameter of the laser drive spot at the front of the target. 
Figure 5 shows how the peak pressure and strain rate scale with laser intensity. The peak intensity is taken as the intensity at the center of the laser spot. On-target laser spot profiles were characterized using a small portion of the light from one of the experimental beams to produce an equivalent target plane (ETP) image of the beam's spatial intensity profile as it would appear on the face of a target at normal incidence. We expect that this ETP image resembles the beam profile for all ten of the beams used in the experiment and that beam-to-beam variations in the spatial intensity profile are small. The on-target laser intensity was modeled using the single-beam laser intensity from Eq. (4) and the orientation of each of the ten drive beams. The resulting intensity delivered to the front face of the target, including the non-normal incidence of each beam, can be described by a super-Gaussian,

$$
I(r)=I_{0} e^{-\left(\frac{r}{507 \mu m}\right)^{425}}
$$

where $r$ is the radius in microns, and $I_{0}$ is the intensity at the center of the spot in $\mathrm{W} / \mathrm{cm}^{2}$. An effective $90 \%-90 \%$ drive area can be defined by setting $\mathrm{I} / \mathrm{I}_{0}=0.9$. The resulting drive spot is $600 \mu \mathrm{m}$ across and $35 \%$ of the total pulse energy delivered to the target is within this diameter. A fit to the pressure data (solid squares) in Fig. 5 gives a linear scaling for this shot series of

$$
P=27 I
$$


where $P$ is the peak pressure in the sample in units of GPa and $I$ is the laser intensity in units of $10^{13} \mathrm{~W} / \mathrm{cm}^{2}$. The scaling constant will change for different reservoir materials or target designs having significantly different dimensions. However, for laser durations considerably shorter than the shock transit time in the reservoir, the scaling is expected to remain linear with laser intensity. The shock transit times for a series of shots are given in Table 2, showing that the transit times are considerably longer than the laser pulse duration.

The dynamic response of materials can be highly dependent upon the strain rate of the deformation process. We can estimate the strain rate in our samples under the loading conditions present in this study. We will assume that the compression in the $\mathrm{Al}$ has relaxed to a symmetric 3D (isotropic) state. [Bringa, 2006] To derive an appropriate strain rate relation, consider a parcel of material of spatial scale $\ell$, from which $\ell \sim \rho^{-1 / 3}$. The strain can then be defined as $\delta \ell / \ell \approx \varepsilon \approx(1 / 3) \delta \rho / \rho$. If $\delta$ t is the time interval over which the density changes by $\delta \rho$, then the strain rate $\mathrm{d} \varepsilon / \mathrm{dt} \approx(1 / 3)(\delta \rho / \rho)(1 / \delta \mathrm{t})=$ $(1 / 3)(\delta \rho / \delta t)(1 / \rho)$. Hence, the plastic strain rate for 3D compression can be written as

$$
\mathrm{d} \varepsilon / \mathrm{dt} \approx \frac{1}{3} \frac{\mathrm{d} \rho / \mathrm{dt}}{\rho}
$$

Strain rate values for the shot series shown in Fig. 4 are shown as filled circles in Fig. 5. The compression waves were simulated in the samples with the CALE hydrocode using the loading histories, $\mathrm{P}(\mathrm{t})$, generated from the VISAR records. These pressure profiles were forward propagated through aluminum-LiF targets of equivalent 
dimensions to those shot on the laser. The plastic strain rate was calculated for three different regions inside the sample for the full duration of loading and unloading. The maximum values for the 3D strain rates are those shown in Fig. 5. The dotted line has been added to guide the eye. These strain rates are significantly lower than strain rates produced in shock loaded samples at equivalent peak pressures. Swegle and Grady calculated strain rates for a number of materials shock loaded to pressures up to several 10's of GPa. [Swegle, 1985] Their analysis suggested a strain rate scaling that varied as the fourth power of the applied stress. Extrapolation of their fit to aluminum would generate strain rates several orders of magnitude higher than those we show here. A power law fit to the modeled strain rates in Fig. 5 shows the strain rate to vary with the pressure as, $\mathrm{d} \varepsilon / \mathrm{dt} \sim \mathrm{P}^{1.4}$, which is a considerably softer scaling with pressure than the Swegle-Grady relation of $\mathrm{d} \varepsilon / \mathrm{dt} \sim \mathrm{P}^{4}$.

\section{B. Transition to a Shock}

The ns-scale rise times for the loading of these samples is quite fast relative to other shockless loading techniques used on gas guns, high explosive facilities and the Zaccelerator. However, we would expect much shorter rise times in the VISAR records for aluminum shock loaded to high pressures. An extrapolation of Swegle and Grady's strain rate scaling in aluminum [Swegle, 1985] would give a rise time of 0.04 ps for a $200 \mathrm{GPa}$ steady shock. Using this metric, the rise times shown for the laser-driven ramped drive shown in this paper are five orders of magnitude longer, and could therefore be considered shock free. The shock rise time for a very strong shock (>100 GPa) in aluminum has not been experimentally measured, so no direct comparison can be made to 
the rise times we are seeing in this study. However, a set of experiments showing the loading wave as it evolves into a shock can confirm that the loading here is shock free and this can provide a bound on the amount of material that can be loaded under shockfree conditions. The VISAR diagnostic used in this study has a temporal resolution of $\sim 200$ ps so for rise times less than 200 ps the VISAR record will show a discontinuous fringe-jump. This would be considered a shock for our purposes here.

Four targets were assembled that varied only in the amount of aluminum deposited onto the LiF windows. Targets were fabricated with aluminum coatings of 5.0, 10.3, 19.8 and $33.5 \mu \mathrm{m}$ on $125 \mu \mathrm{m} \mathrm{LiF}$ windows. Since the LiF is nearly impedance matched to the aluminum, and is significantly thicker than the coatings, this set of measurements is comparable to taking particle velocity measurements at four different depths inside a thick $(\sim 130 \mu \mathrm{m})$ sample of target material. The four targets were shot at laser energies of $1235,1262,1253$ and $1196 \mathrm{~J}$, corresponding to a laser intensity of $4.57 \times 10^{13} \pm 1 \% \mathrm{~W} / \mathrm{cm}^{2}$. The details of these shots are given at the bottom of Table 1. Figure 6 shows VISAR records of the $\mathrm{Al}-\mathrm{LiF}$ interface motion for each of the four shots. These images were cropped from the larger original records to a size corresponding to 10ns (horizontal) by $200 \mu \mathrm{m}$ (vertical). The records are arranged clockwise from (a) to (d) in order of increasing sample thickness. The first three images clearly show a steepening in the loading as the sample becomes progressively thicker. The onset of the shock can be seen in image (c) where the foot of the wave has steepened and is followed by a more gentle velocity rise. At a depth of $33.5 \mu \mathrm{m}$, image (d) shows a definite discontinuity in the fringe record that is characteristic of a loading time that is shorter than the resolution time of the diagnostic. The maximum fringe shift is equal for all shots, indicating that they all 
reached the same peak particle velocity. The fringe shift for case (d) can be determined unambiguously since the particle motion was recorded on two interferometers having different sensitivities. For this case, shifts of 0.79 and 1.76 fringes in the two different interferometers give an equivalent velocity jump of $2.9 \mathrm{~km} / \mathrm{s}$.

The extracted particle velocities give an even clearer picture of the steepening of the loading wave into a shock. Figure 7a shows measured (thick gray curves) and simulated (dashed curves) particle velocities reduced from the VISAR records shown in Fig. 6. (See Table 1 for details.) In reducing the VISAR records, the experimental velocity profiles were spatially averaged over $\sim 200 \mu \mathrm{m}$. The experimental record for the $10.3 \mu \mathrm{m}$ case (trace b) was shifted earlier in time by $0.45 \mathrm{~ns}$ to account for a timing discrepancy (explanation below). This experimental shot series provides a set of "snapshots" of the high-pressure compression wave as it evolves into a shock. As the wave moves through the material, the leading edge of the wave steepens first. Up to a depth of $20 \mu \mathrm{m}$ the VISAR records show smooth loading in the samples with no shock discontinuities. The shock transition is clearly seen in the last particle velocity trace. At a depth of $33.5 \mu \mathrm{m}$ the particle velocity jumps to $2.9 \mathrm{~km} / \mathrm{s}$ (shown by a vertical dashed line). This velocity corresponds to a shock pressure of $80 \mathrm{GPa}$ on the principal Hugoniot of aluminum. At this depth, the material is shocked to $80 \mathrm{GPa}$ and then loads shocklessly up to a peak pressure of $120 \mathrm{GPa}$. As the wave propagates further into the sample, the shock amplitude will increase to its maximum value of $120 \mathrm{GPa}$.

We modeled the evolution of the compression wave through the sample, using the experimental data as a constraint. The simulated particle velocity for the $5 \mu \mathrm{m}$ case (trace a) was obtained by back-integrating the measured particle velocity using a Grüneisen 
EOS [Walsh, 1957] to obtain a pressure-time loading history at the front face of the sample. This load, $\mathrm{P}(\mathrm{t})$, (where $\mathrm{P}$ is pressure applied at the front surface of the sample) was then forward propagated through a thick sample $(>100 \mu \mathrm{m})$ of aluminum using the CALE hydrodynamic code [Barton, 1985] and a tabular EOS which closely matches a Grüneisen EOS model of aluminum under these conditions. Independent hydrodynamic simulations of the four laser shots showed that the absolute timing for the $10.3 \mu \mathrm{m}$ case (trace b) was in disagreement with the other cases. Diagnostic and laser jitter for these shots is typically less than $100 \mathrm{ps}$, and timing records could not pinpoint the $\sim 0.5 \mathrm{~ns}$ discrepancy. We therefore, shifted the entire record for this target by $-0.45 \mathrm{~ns}$ in order to remain consistent with the other shot data. No other details of the particle velocity trace (such as the shape) were altered. Simulated particle velocity profiles (dashed curves) for the experimental depths equivalent to the target sample thicknesses have been overlaid onto the experimental data (gray curves).

The hydrodynamic simulations are in very good agreement with both the shape and absolute timing (with the exception of the unadjusted $10.3 \mu \mathrm{m}$ experimental case) for the experimental particle velocities of these thicker aluminum samples, validating the back integration procedure, at least to within the measurement uncertainty. We back integrated the $5 \mu \mathrm{m}$ aluminum case on the assumption that it was isentropic, then hydrodynamically propagated this ideal pressure wave, $\mathrm{P}(\mathrm{t})$, forward through thicker aluminum and compare the simulated particle velocity with the experimental record. If the original back integration from the thin aluminum sample had been strongly affected by heat conduction from the front surface, then the back integration would have been "contaminated". The preheated $5 \mu \mathrm{m}$ of $\mathrm{Al}$ would have been less compressible, and the forward hydrodynamic 
propagation would have then under-predicted the peak particle speeds (compressions) for the other traces representing the thicker samples. In fact, the simulated particle velocities are in excellent agreement with the experimental wave profiles. This agreement suggests that, at least in terms of compressibility, the loading is not observably different from the room temperature isentrope.

As a consistency check, the pressure profiles at the front of the Al, determined by back integrating each of the experimental velocity traces shown in Fig. 7a, for each sample thickness, are shown in Fig. 7b. Note that the three "shock-free" cases show nearly identical loading, to within the experimental uncertainties. The 33.5 um case (gray dots) was back integrated by artificially inserting a $100 \mathrm{ps}$ ramp into the portion of the particle velocity record where the shock discontinuity exists. This pressure profile clearly shows a deviation from the loading in the other cases, especially in the late-time release portion of the wave.

\section{DISCUSSION}

\section{A. Temperature Effects}

Hydrodynamic calculations that have been calibrated to experimental data, such as the VISAR data, can provide information about the high-pressure state of the material that would otherwise be difficult to measure directly. The temperature behind the loading wave is a material parameter that is particularly difficult to measure. Nonetheless, temperature effects can have a significant influence on, for example, the material strength. The temperature can rise due to viscous heating from the plastic flow, PdV work of compression, from increased entropy behind the shock front, or from the heat 
generated from the stagnating reservoir. The time scales for the loading and compression are rapid enough that the process may be considered adiabatic. In that case any energy not put into residual deformation will raise the temperature of the material behind the wave. We first use the simulations to estimate the effects of material strength on the measurements. The measured particle velocity, $\mathrm{u}_{\mathrm{p}}(\mathrm{t})$, for the $120 \mathrm{GPa}$ experiment for the $10.3 \mu \mathrm{m}$ thick $\mathrm{Al}$ case is shown in Fig. 8 by the open circles. This trace was back integrated to determine a driving pressure, $\mathrm{P}(\mathrm{t})$, at the front face of the sample, which was then used as input in a 1D hydrodynamic code to forward propagate the loading wave and regenerate the particle velocity at a sample thickness of $10.3 \mu \mathrm{m}$. The forward propagation assumed no material strength in the sample, demonstrating that the experimental particle velocities (and hence, compression) are insensitive to strength issues within the limits of the experimental resolution, at least at these pressures. Strength effects are more significant for the material temperature. The two lower curves show temperature versus time outputs for the same simulation for the case without strength (dot-dashed) and the case with strength (dashed). The simulation with strength used a standard Steinberg-Guinan constitutive model, [Steinberg, 1980] and shows $~ 10 \%$ higher temperatures due to the work done against the material strength, which goes into viscous heat generation.

The rise in temperature in the sample will be significantly greater for the case of a sample that has been shock loaded compared to one that has been ramp-loaded along a path close to the isentrope. Figure 9a shows the simulated temperature and compression as a function of time in a compressed aluminum sample at depths (5.0, 10.3, 19.8 and $33.5 \mu \mathrm{m})$ equal to the thickness of the layers used in the experimental samples loaded to 
120 GPa. Simulations were carried out using the CALE hydrocode. Note, that these simulations take a pressure profile, $\mathrm{P}(\mathrm{t})$, derived from back-integrating the VISAR record shown in Fig. 6a, and propagating the loading wave through a "cold" sample of aluminum. As shown in Fig. 9a, at pre-shock depths of $20 \mu \mathrm{m}$ or less, the temperature in the aluminum peaks at $725-750 \mathrm{~K}$. This is below the ambient melt temperature of $933 \mathrm{~K}$ for aluminum. Since the melt temperature increases with compression (pressure), the calculations indicate that the sample remains at about a fourth of the melt temperature, $\mathrm{T}_{\mathrm{Al}} \approx \mathrm{T}_{\text {melt }} / 4$, at a depth of $20 \mu \mathrm{m}$. At depths beyond $\sim 25 \mu \mathrm{m}$ the temperature rises rapidly indicating the rapid heating effects associated with strong shocks. The temperature rises to about $2000 \mathrm{~K}$ at a depth of $33.5 \mu \mathrm{m}$. At this depth the shock strength was estimated to be $\sim 80 \mathrm{GPa}$ from the particle velocity (trace d) in Fig. 7a. Standard shock tables give values of $\sim 2500 \mathrm{~K}$ for aluminum shocked to $80 \mathrm{GPa}$. The compression, $\rho / \rho_{0}$, behind the loading wave undergoes a much less dramatic change when the wave transitions to a shock. The compression at all four depths appears to be asymptoting to about the same value of 1.67. On close inspection the compression at $33.5 \mu \mathrm{m}$ of $\sim 1.65$ is slightly less due to the heating. One can see that the presence of a shock might have only small effects on the compressibility at these pressures, but the $\sim 3 \mathrm{x}$ rise in temperature could have significant effects on other properties, such as the material strength.

This same analysis can be applied to the $200 \mathrm{GPa}$ case. We used the particle velocity profile from the VISAR record along with an aluminum EOS [Nellis, 2003] to generate a loading history at the front of the sample package (see Fig. 3b). The simulated loading wave was propagated through an aluminum sample and the pressure and temperature were tracked in order to determine the onset of shock loading. Figure $9 \mathrm{~b}$ shows the 
pressure (solid curves) and temperature (dashed curves), as a function of the depth in the sample, at 16, 16.6, 17 and $17.6 \mathrm{~ns}$ after the laser fires. Notice that the pressure wave develops a low amplitude shock about $17 \mu \mathrm{m}$ into the sample. At this point the residual temperature just behind the shock front begins to increase. At a depth of $23 \mu \mathrm{m}$ the shock amplitude is just under $100 \mathrm{GPa}$ (half the peak loading amplitude), and the heat deposited at the shock front is enough to raise the temperature to $\sim 2500 \mathrm{~K}$, or about 0.6 of the melt temperature at $100 \mathrm{GPa}$. This residual heat will eventually spread throughout the target and can be large enough to melt the sample after the pressure is released. In this $200 \mathrm{GPa}$ case the loading begins to form a shock in a little less than $20 \mu \mathrm{m}$, and develops into a full $200 \mathrm{GPa}$ shock at a depth of $\sim 30 \mu \mathrm{m}$.

\section{B. Limitations to peak pressures and sample thicknesses}

Shock-free loading in aluminum extends on order of a few 10's of microns into the sample for loads reaching $100 \mathrm{GPa}$ to over a hundred microns for loads near $10 \mathrm{GPa}$ for the laser-target configuration outlined in this study. For very high pressures the shock wave will generate enough heat behind the wave front to cause incipient melt. Melting from irreversible shock heating is a primary limiting factor in high-pressure materials deformation studies. Figure 10 shows the distance a loading wave from this drive can propagate into an aluminum sample, as a function of peak pressure, before it begins to transition to a shock. The shock region is divided into two sections - shocked and shock melted. The dividing line was placed at $120 \mathrm{GPa}$. Above this pressure, modeling indicates that melting occurs in aluminum under single shock conditions on the Hugoniot. The shock distances were calculated using the pressure-time profiles shown in Fig. 4. The 
shock distance was correlated to the calculated temperature in the sample. Temperaturetime plots were calculated at $5 \mu \mathrm{m}$ intervals. The first significant rise in temperature was assigned as the point of shock onset. The simulations shown in Figure 7a, for example, for the $120 \mathrm{GPa}$ drive give a shock depth of about $25 \mu \mathrm{m}$. Calculations for the $14 \mathrm{GPa}$ drive show the shock depth to be over $150 \mu \mathrm{m}$. This is a sufficient distance for investigation of the dynamic response of bulk materials under shock-free loading conditions on a laser.

Figure 10 also shows the effects of heating from the reservoir material, which becomes heated as it stagnates against the front of the sample and converts its directed kinetic energy into thermal energy. The barred area on the left-hand side of Fig. 10 shows the amount of material that is predicted to melt at the front face of the sample as a result of this, in the absence of any heat shield layer (such as $\mathrm{CH}$ ). These results were obtained from LASNEX [Zimmerman, 1975] simulations, which modeled the entire drive including the laser deposition on the front of the reservoir, and which matched the measured particle velocities at the Al-LiF interface. The melt distances shown were estimated at the time of peak loading (see Fig. 4) using a Lindemann melt law. [Steinberg, 1980] To quantify this further we follow the evolution of a target loaded to $120 \mathrm{GPa}$ (See Figs. 7a and 9a). Within $10 \mathrm{~ns}$ of the onset of sample loading, the pressure at the front of the sample has peaked at $120 \mathrm{GPa}$. At this point about $2 \mu \mathrm{m}$ of sample material has melted, but the heating from stagnating inflowing reservoir has only reached $20 \%$ of the melt temperature at a depth of $5 \mu \mathrm{m}$. In another $5 \mathrm{~ns}$, the loading wave has advanced to a depth of 30 microns and shock formation is beginning. The shock wave grows as it propagates into the sample, irreversibly heating the material as it passes. 
Temperatures gradually increase to just above the melt temperature at $35 \mathrm{~ns}$ after the onset of loading and at a depth of $\sim 120-160 \mu \mathrm{m}$. By this time, the thermal load from the reservoir has melted $\sim 10 \mu \mathrm{m}$ of material. At late times, when the load begins to release, additional melting can be expected in regions where irreversible heating is sufficient to raise the temperature of the sample above the ambient melt temperature.

Melting, at the front of the sample, can be eliminated or delayed in time by using a small amount of sacrificial heat shield material that is applied to the front face of the sample to absorb the heat from reservoir stagnation, but otherwise perturbing the loading dynamics little. We have applied small amounts $(5 \mu \mathrm{m})$ of $\mathrm{CH}$ (Parylene) to the drive side of several target samples to test whether melt from the drive could be depressed or eliminated. These targets were driven to pressures of up to $\sim 90 \mathrm{GPa}$, soft recovered, and studied using optical imaging and TEM. It was determined that $5 \mu \mathrm{m}$ of thermal barrier was sufficient to eliminate any melt in cases where the peak pressure was less than 30 GPa. [McNaney, 2004] Above this loading pressure sample melting was observed but was predicted to occur at times very much later than when typical dynamic measurements would be made. The extent of the central region in Fig. 10 summarizes the efficacy of the current laser-target configuration for producing shock-free loading in aluminum.

\section{SUMMARY}

We have developed a laser-driven shockless loading technique for studying material behavior under dynamic, high-pressure conditions. In this paper, we have demonstrated shockless loading in thin aluminum foils at pressures of 14-200 GPa. The peak pressures achievable in aluminum depend on the laser intensity as $\mathrm{P}=27 \mathrm{I}$, where $\mathrm{P}$ 
is the pressure in GPa, and I is the laser intensity in $10^{13} \mathrm{~W} / \mathrm{cm}^{2}$. A series of VISAR records for progressively thicker samples taken under identical loading conditions provides a set of "snapshots" of the evolution of a $120 \mathrm{GPa}$ compression wave propagating through aluminum and transitioning into a shock. For drives reaching 120 GPa, material in the sample remained shockless to depths of $\sim 25 \mu \mathrm{m}$. At peak loads approaching $200 \mathrm{GPa}$ - well past the estimated shock melting pressure of $120 \mathrm{GPa}$, modeling showed that the material up to $\sim 20 \mu \mathrm{m}$ in the target was loaded without shocks.

A number of modifications are being studied that will increase the amount of sample that can be loaded without shocks. Straightforward solutions include increasing the gap distance and the laser pulse duration. A more effective and elegant solution involves shaping the loading wave by using a graded-density reservoir to shape the density of the unloading reservoir material as it propagates across the vacuum gap. [Smith, 2006] Finally, we can look to the laser to do the work of tailoring the loading profile. The need for pulse shaping is widely recognized for a variety of laser-driven applications, including inertial confinement fusion studies. [Lindl, 1995] The NIF laser has demonstrated the capability of generating pulses that are 10's of ns long where the time-dependent intensity can be finely tailored. This capability is being exploited in our design work to make this shockless driver able to achieve still higher peak pressures, lower strain rates and longer shock-up distances.

\section{ACKNOWLEDGMENTS}

We extend our appreciation to the staff at the Laboratory for Laser Energetics for help with these experiments, and to Hedley Louis and Russell Wallace for the fabrication 
of the laser targets. This work was performed under the auspices of the U.S. Department of Energy by the Lawrence Livermore National Laboratory under contract No. W-7405ENG-48. 


\section{References}

[Akahama, 2006] Y. Akahama, M. Nishimura, K. Kinoshita, and H. Kawamura, "Evidence of a fcc-hcp transition in aluminum at multimegabar pressure," Phys. Rev.

Lett. 96, 04505 (2006).

[Asay, 1997] J. R. Asay, “The use of shock-structure methods for evaluating highpressure material properties," Int. J. Impact Engng. 20, 27 (1997).

[Barnes, 1974] J. F. Barnes, P. J. Blewett, R. G. McQueen, K. A. Meyer and D. Venable, “Taylor instability in solids,” J. Appl. Phys. 45, 727 (1974).

[Barnes, 1980] J.F. Barnes, D.H. Janney, R.K. London, K. A. Meyer, and D.H. Sharp, "Further experimentation on Taylor instability in solids," J. Appl. Phys. 51, 4678 (1980). [Barton, 1985] R. T. Barton, Numerical Astrophysics, Jones \& Bartlett, Boston, 1985. [Boehly, 1997] T. R. Boehly, D. L. Brown, R. S. Craxton, R. L. Keck, J. P. Knauer, J. H. Kelly, T. J. Kessler, S. A. Kumpan, S. J. Loucks, S. A. Letzring, F. J. Marshall, R. L. McCrory, S. F. B. Morse, W. Seka, J. M. Soures, and C. P. Verdon, "Initial performance results of the OMEGA laser system," Opt. Commun. 133, 495 (1997).

[Boettger, 1996] J.C. Boettger and S.B. Trickey, "High-precision calculation of the equation of state and crystallographic phase stability for aluminum,” Phys. Rev. B 53, 3007 (1996).

[Bringa, 2006]. E. M. Bringa, K. Rosolankova, R. E. Rudd, B. A. Remington, J. S. Wark, M. Duchaineau, D. H. Kalantar, J. Hawreliak, \& J. Belak, "Shock deformation of fcc metals on sub-nanosecond time scales," submitted, Nature Materials (May, 2006). 
[Celliers, 1998] P. M. Celliers, G. W. Collins, L. B. Da Silva, D. M. Gold and R. Cauble, "Accurate measurement of laser-driven shock trajectories with velocity interferometry," Appl. Phys. Lett. 73, 1320 (1998).

[Celliers, 2004] P. M. Celliers, D. K. Bradley, G. W. Collins, and D. G. Hicks, T. R. Boehly and W. J. Armstrong, "Line-imaging velocimeter for shock diagnostics at the OMEGA laser facility," Rev. Sci. Instrum. 75, 4916 (2004).

[Edwards, 2004] J. Edwards, K.T. Lorenz, B. A. Remington, S. Pollaine, J. Colvin, D. Braun, B. F. Lasinski, D. Reisman, J.M. McNaney, J. A. Greenough, R.Wallace, H. Louis, and D. Kalantar, “Laser-Driven Plasma Loader for Shockless Compression and Acceleration of Samples in the Solid State,” Phys. Rev. Lett. 92, 075002 (2004).

[Guillot, 1999] Tristan Guillot, "Interiors of Giant Planets Inside and Outside the Solar System," Science 286, 72 (1999).

[Hall, 2001] C. A. Hall, J. R. Asay, M. D. Knudson, W. A. Stygar, R. B. Spielman, T. D. Pointon, D. B. Reisman, A. Toor, and R. C. Cauble,, "Experimental configuration for isentropic compression of solids using pulsed magnetic loading," Rev. Sci. Instrum. 72, 3587 (2001).

[Hayes, 2001a] D. Hayes, Backward Integration of the Equations of Motion to Correct for Free Surface Perturbations, Sandia Report SAND2001-1440 (2001).

[Hayes, 2001b] Dennis Hayes, "Unsteady compression waves in interferometer windows," J. Applied Phys. 89, 6484 (2001).

[Hayes, 2004] D. B. Hayes, C. A. Hall, J. R. Asay, and M. D. Knudson, "Measurement of the compression isentrope for 6061-T6 aluminum to $185 \mathrm{GPa}$ and $46 \%$ volumetric strain using pulsed magnetic loading," J. Appl. Phys. 96, 5520(2004). 
[Hogan, 2001] W. Hogan, E. Moses, B. Warner, M. Sorem, J. Soures, “The National Ignition Facility,” Nucl. Fusion 41, 567 (2001).

[Jankowski, 2005] A. Jankowski, J. Ferreira, and J. Hayes, “Activation energies of grain growth mechanisms in aluminum coatings," Thin Solid Films 491 (1-2): 61-65 (NOV 22 2005).

[Jankowski, 2004] A. Jankowski, and J. Hayes, "The evaporative deposition of aluminum coatings and shapes with grain size control," Thin Solid Films 447: 568-574 (JAN 30 2004).

[Knudson, 2005] M.D. Knudson, J.R. Asay, and C. Deeney, “Adiabatic release measurements in aluminum from 240- to 500-GPa states on the principal Hugoniont," J. Appl. Phys. 97, 073514 (2005).

[Lindl, 1995] J. Lindl, "Development of the indirect-drive approach to inertial confinement fusion and the target physics basis for ignition and gain," Phys. Plasmas 2, 3933 (1995).

[McNaney, 2004] J. M. McNaney, M. J. Edwards, R. Becker, K. T. Lorenz, and B. A. Remington, "High-pressure, laser-driven deformation of an aluminum alloy," Met. Mat. Trans. A, 35A, 2625 (2004).

[McQueen 1970] R.G. McQueen, S.,P. Marsh, J.W. Taylor, J.N. Fritz, and W.J. Carter, in High-Velocity Impact Phenomena, Ed. Ray Kinslow (Academic Press, New York, 1970), pp. 293.

[Mitchell 1981] A.C. Mitchell and W.J. Nellis, "Shock compression of aluminum, copper, and tantalum,” J. Appl. Phys. 52, 3363 (1981). 
[Moriarty, 1995] John A. Moriarty and J.D. Althoff, "First-principles temperaturepressure phase diagram of magnesium," Phys. Rev. B 51, 5609 (1995).

[Nellis, 2003] W. J. Nellis, A. C. Mitchell and D. A. Young, "Equation-of-state measurements for aluminum, copper, and tantalum in the pressure range 80-440 GPa (0.8-4.4 Mbar),” J. Appl. Phys. 93, 304 (2003).

[Nguyen, 2004] Jeffrey H. Nguyen, Daniel Orlikowski, Frederick H. Streitz, Neil C. Holmes and John A. Moriarty, "Specifically prescribed dynamic thermodynamic paths and resolidification experiments," proceedings of the APS-SCCM-03 (2004).

[Raevsky, 2006] V. Raevsky, private commun. (2006).

[Reisman, 2001] D. B. Reisman, A. Toor, and R. C. Cauble, C. A. Hall, J. R. Asay, M. D. Knudson, and M. D. Furnish, "Magnetically driven isentropic compression experiments on the $\mathrm{Z}$ accelerator,” J. Appl. Phys. 89, 1625 (2001).

[Reisman, 2004] D. B. Reisman, LLNL, L-099, Livermore, CA, private communication (2004).

[Remington, 2004] B.A. Remington, G. Bazan, J. Belak, E. Bringa, M. Caturla, J. Colvin, M.J. Edwards, S.G. Glendinning, B. Kad, D.H. Kalantar, M. Kumar, B.F. Lasinski, K.T. Lorenz, J. McNaney, M.A. Meyers, S.M. Polaine, D. Rowley, M.S. Schneider, J. Stolken, J. Wark, S.V. Weber, W.G. Wolfer, and B. Yaakobi, "Materials Science Under Extreme Conditions of Pressure and Strain Rate," Met. Mat. Trans. 35A, 2587 (2004).

[Remington, 2005] B.A. Remington, R.M. Cavallo, M.J. Edwards, D.D.-M. Ho, K.T. Lorenz, H.E. Lorenzana, B.F. Lasinski, J.M. McNaney, S.M. Pollaine, R.F. Smith, "Accessing high pressure states relevant to core conditions in the giant planets," Astrophysics and Space Science 298, 235-240 (2005). 
[Remington, 2006] Bruce A. Remington, Patrick Allen, Eduaro M. Bringa, Jim

Hawreliak, Darwin Ho, K. Thomas Lorenz, Hector Lorenzana, James M. Mcnaney, Marc A. Meyers, Stephen W. Pollaine, Katarina Rosolankova, Babak Sadik, Matthew S. Schneider, Damian Swift, Justin Wark, Barukh Yaakobi, "Material dynamics under extreme conditions of pressure and strain rate," Materials Science and Technology 22, 474-488 (2006).

[Smith, 2006] Raymond F. Smith, K. Thomas Lorenz, Darwin Ho, Bruce A. Remington, Alex Hamza, John Rogers, Stephen Pollaine, Seokwoo Jeon, Yun-Suk Nam, J. Kilkenny, "Graded-density reservoirs for accessing high pressure low temperature material states," submitted, Astrophys. Space Sci. (2006).

[Steinberg, 1980] D. J. Steinberg, S. G. Cochran and M. W. Guinan, “A constitutive model for metals applicable at high-strain rate," J. Appl. Phys. 51, 1496 (1980). [Swegle, 1985] J. W. Swegle and D. E. Grady, "Shock viscosity and the prediction of shock wave reise times," J. Appl. Phys. 58, 692 (1985).

[Walsh, 1957] J.M. Walsh, M.H. Rice, R.G. McQueen, and F.L. Yarger, "Shock-wave compressions of twenty-seven metals. Equations of State of metals," Rhys. Rev. 108, 196 (1957).

[Wise, 1986] J. L. Wise and L. C. Chhabildas, Shock Waves in Condensed Matter 1985, Y. M. Gupta, ed., pp. 441-454, Plenum, New York, 1986.

[Young, 1991] D.A. Young, Phase Diagrams of the Elements, U. of California Press, Berkeley, CA, 1991.

[Zimmerman, 1975] G. B. Zimmerman and W. L. Kruer, Comments Plasma Phys. Control. Fusion 2, 51 (1975). 


\section{Table Captions}

Table 1. Laser and target shot details for the results shown in Figs. 4 and 5. A) The top half of the table corresponds to Figs. 4 and 5. B) The bottom half of the table corresponds to Figs. 6 and 7. The columns correspond to the curve labels in Figs. 4 and 7, shot number, target reservoir thickness, gap size, Al sample thickness, laser energy, laser intensity on target, and peak pressure at the Al-LiF interface in the sample, respectively. The reservoir details are given at the bottom of the table.

Table 2. Laser and target shot details for a series of shock breakout measurements on reservoir-only targets (no Al-LiF sample separated by a gap). The columns correspond to shot number, reservoir composition, incident laser intensity, and shock breakout times, respectively. Shots with more than one row of entries had steps machined into the $\mathrm{CH}(\mathrm{Br})$ on the back side, facing the VISAR diagnostic.

\section{Figure Captions}

Figure 1 - Schematic pressure-temperature $(\mathrm{P}-\mathrm{T})$ phase diagram for $\mathrm{Al}$. The lower horizontal axis give pressure, and the upper horizontal axis gives compression assuming the room temperature isotherm from [Boettger, 1996]. Superposed are curves showing the melt temperature vs. compression (upper dotted curve), T vs P along the Hugoniot (heavy dotted curve), 3-staged shock T vs P trajectory (dot-dashed curve), and the P-T curve along the room temperature isentrope (dashed curve). The shaded region corresponds to the P-T space for Al in the solid state. [Asay, 1997] The fcc-to-hcp and hcp-to-bcc transitions are based on the predictions and observations described in 
[Akahama, 2006; Boettger, 1996; Moriarty, 1995].

Figure 2 - Schematic diagram of the target configurations used for VISAR drive measurements experiments. The laser drives an ablative shock through a 200 $\mu \mathrm{m}$ thick brominated polystyrene disc, where it adiabatically unloads at the vacuum gap interface. This $300 \mu \mathrm{m}$ wide vacuum gap allows the reservoir material to expand as it propagates across to the sample, resulting in a soft and continuous pressure rise in the sample. The sample loading kinematics are measured using a surrogate sample - an aluminum layer on a $\mathrm{LiF}$ window. In situ particle velocity measurements are made using velocity interferometry (VISAR). These particle velocity records are then transformed to a stress vs time record.

Figure 3 - Shock-free loading of aluminum to $200 \mathrm{GPa}$. (a) Line VISAR record showing the motion of the $\mathrm{Al}-\mathrm{LiF}$ interface as a function of time (horizontal axis) and position (vertical axis) on the target. Fringe motion indicates a change in the velocity of the reflecting $\mathrm{Al}-\mathrm{LiF}$ interface. In this case, one fringe jump equals a change in velocity of $5.46 \mathrm{~km} / \mathrm{s}$. The fringe motion shows smooth, continuous acceleration followed by a slower deceleration as the loading wave passes through the $\mathrm{Al}$ sample and into the $\mathrm{LiF}$ window. (b) Particle velocity (lower curve) and extracted pressure (upper curve) taken from the VISAR record in (a). Heavy solid lines show velocity and extracted pressure averaged over 300 microns. Shading shows error bars generated from a spatial analysis of six velocity records - one taken every 50 pixels. Shading represents $90 \%$ confidence limits for both particle velocity and pressure. Over the peak drive window $(t=20-30 \mathrm{~ns})$, the average deviation in particle velocity and pressure are $3.6 \%$ and $5.5 \%$, respectively. 
Figure 4 - Pressure histories for a series of Al targets driven by increasingly higher pulse energies. Shock-free loading was generated in samples using single laser shots consisting of 10 overlapping beams and having pulse durations of $3.7 \mathrm{~ns}$ The $200 \mathrm{GPa}$ load was achieved using $\sim 2 \mathrm{~kJ}$ of laser energy. The laser intensities and other shot details for curves a-e are given in Table 1.

$\underline{\text { Figure } 5}$ - Pressure and strain-rate scaling as a function of laser intensity. The peak pressure delivered to the sample scales directly with the laser intensity delivered to the ablation layer on the front of the reservoir (see Fig.4). Strain rates are 10-100 times larger than shockless techniques using high-explosives or pulsed power, but are orders of magnitude smaller than those predicted under shock loading conditions.

Figure 6 - A series of VISAR records, for successively thicker samples, shows the evolution of a ramped pressure wave as it evolves into a strong shock. All four Al samples were driven under identical laser conditions to a peak pressure of $120 \mathrm{GPa}$. Sample thicknesses were 5.0, 10.3, 19.8 and $33.5 \mu \mathrm{m}$ for (a) - (b), respectively. The shot details are given in Table 1. The loading wave that begins as a smoothly increasing pressure profile in (a) has steepened into a strong shock of $80 \mathrm{GPa}$ at a depth of $\sim 34 \mu \mathrm{m}$ shown by the discontinuity in the fringe record in (d). Figure 7 - Analysis of VISAR records from Fig. 6. (a) Experimental data is shown as solid gray lines. The shot details are given in Table 1. Trace $\mathrm{b}$ was back integrated to generate a stress-time history on the front of the $\mathrm{Al}$ sample, which was then used as input in a hydrodynamic package to simulate the particle velocity through a thick sample. The dashed lines show the simulated particle velocities taken at foil depths of 5.0, 10.3, 19.8 and $33.5 \mu \mathrm{m}$ - equal to the thickness of the experimental samples. The same procedure 
was carried out using trace a and trace c. Both of those analyses gave similar results to those shown here. (b) Plot of the applied stress versus time at the front of the aluminum samples, generated by back integrating each of the experimental velocity traces shown in (a). Note that traces (a)-(c) lie show nearly identical loading for the three separate laser shots. Trace (d) deviates from the other traces because the back-integration method fails for the initial conditions represented by a strong shock- a discontinuous jump in particle velocity.

Figure 8 - Affect of material strength on the temperature and particle velocity. The upper trace shows the experimental particle velocity (open circles) for the $10.3 \mu \mathrm{m}$ target loaded to $120 \mathrm{GPa}$. This trace was back integrated to determine a driving pressure, $\mathrm{P}(\mathrm{t})$, at the front face of the sample, which was then used as input in a 1D hydrodynamic code to forward propagate the loading wave and regenerate the particle velocity at a sample thickness of $10.3 \mu \mathrm{m}$. The forward propagation assumed no material strength in the sample, demonstrating that the experimental particle velocities are insensitive to strength issues within the limits of the experimental resolution. Strength effects are more significant for the material temperature. The two lower curves show temperature versus time outputs for the same simulation for the case without strength (dot-dashed) and the case with strength (dashed). The simulation with strength used a standard SteinbergGuinan constitutive model. [Steinberg, 1980]

Figure 9 - Simulated internal state properties of the high-pressure states in aluminum generated with the shockless driver presented in this paper. (a) Compression, $\rho / \rho_{0}$, and temperature versus time profiles for the $120 \mathrm{GPa}$ loading wave series shown in Fig. 6. As the loading wave transitions to a strong shock, the compression at that depth in the 
sample shows a slight lower compression compared to the shock-free positions. The temperature at the shocked position shows a more noticeable temperature increase. (b) Simulated pressure and temperature versus position profiles for the $200 \mathrm{GPa}$ loading wave shown in Fig. 3a. Traces, from left to right, represent the pressure (solid lines) and temperature (dashed lines) through the sample at 16, 16.6, 17 and $17.6 \mathrm{~ns}$ after the drive laser turns on.

$\underline{\text { Figure } 10}$ - Heating and shock effects in the current laser-driven dynamic loading experiments. Regions of melting and shock-processing as a function of sample depth and peak pressure are shown for aluminum. Melting at the front face of the sample, due to stagnation heating as the reservoir material piles up against the sample, is shown as the vertical-bar area. At large sample depths the loading wave evolves into a shock that generates additional heating. This area is shown in the upper right corner. For singleshock pressures greater than $120 \mathrm{GPa}$, aluminum is expected to promptly melt under the shock front (diagonal hatching). 
Table 1: Target and laser drive details

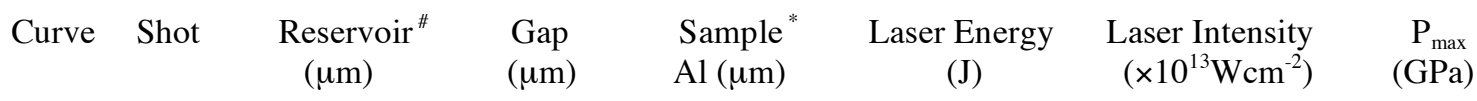

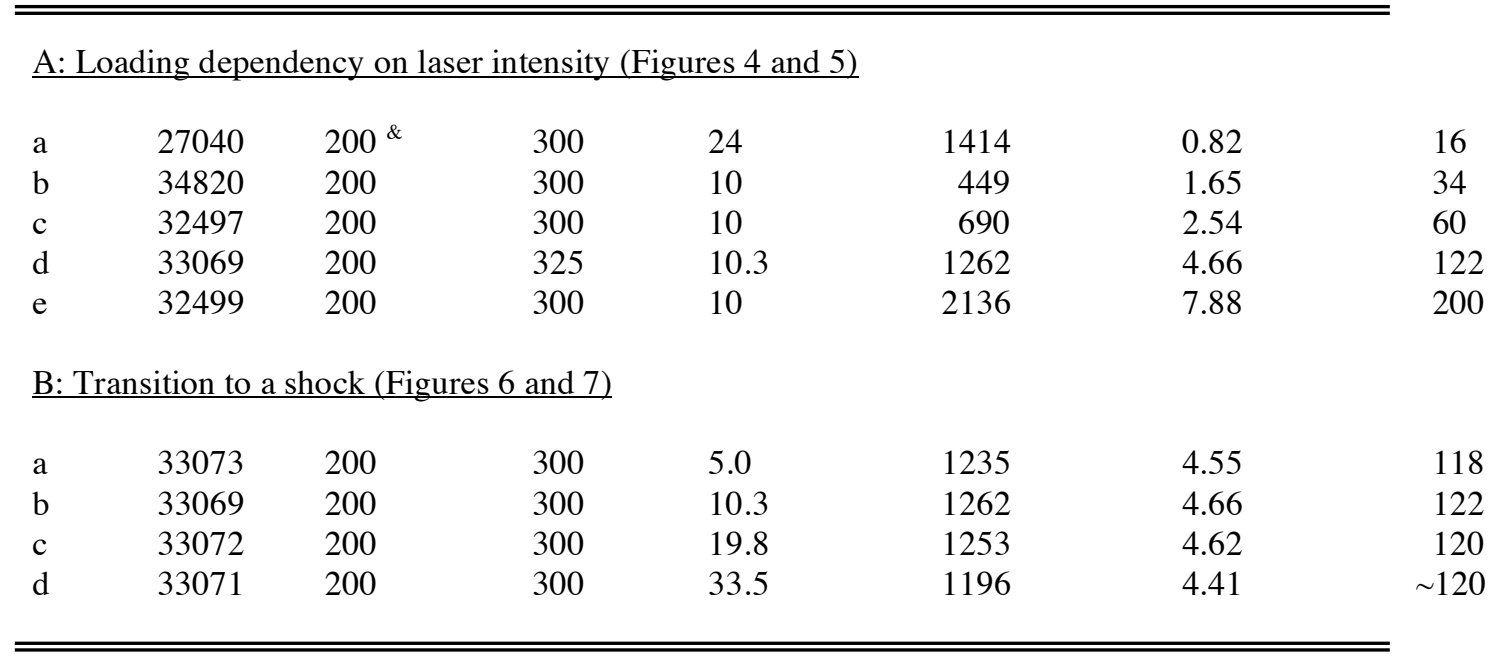

${ }^{\#} 28 \mu \mathrm{m}$ polyimide ablator $\left(\mathrm{C}_{22} \mathrm{H}_{10} \mathrm{~N}_{2} \mathrm{O}_{5}, 1.60 \mathrm{~g} / \mathrm{cc}\right)$ plus $170 \mu \mathrm{m}$ of $12.5 \% \mathrm{BrCH}\left(\mathrm{C}_{8} \mathrm{H}_{6} \mathrm{Br}_{2}, 2.0 \mathrm{~g} / \mathrm{cc}\right)$

\& $20 \mu \mathrm{m}$ polycarbonate ablator $\left(\mathrm{C}_{16} \mathrm{H}_{18} \mathrm{O}_{4}, 1.20 \mathrm{~g} / \mathrm{cc}\right)$ plus $180 \mu \mathrm{m}$ of $2 \% \mathrm{BrCH}\left(\mathrm{C}_{50} \mathrm{H}_{48} \mathrm{Br}_{2}, 1.23 \mathrm{~g} / \mathrm{cc}\right)$

* Samples were Al deposited onto $125 \mu \mathrm{m} \mathrm{LiF}$.

Table 2: Shock transit times

Shot Reservoir $\quad$ Laser Intensity (W/cm2) Breakout (ns)

3249528 um $\mathrm{PI}+170$ um $12.5 \% \mathrm{CH}(\mathrm{Br}) \quad 1.62 \mathrm{e} 13 \quad 10.78$

3306228 um $\mathrm{PI}+120$ um $12.5 \% \mathrm{CH}(\mathrm{Br}) \quad 1.75 \mathrm{e} 13 \quad 5.68$

+145 um $12.5 \% \mathrm{CH}(\mathrm{Br})$

+170 um $12.5 \% \mathrm{CH}(\mathrm{Br})$

3306428 um $\mathrm{PI}+170$ um $12.5 \% \mathrm{CH}(\mathrm{Br}) \quad 3.45 \mathrm{e} 13 \quad 8.85$

3306528 um PI +100 um $12.5 \% \mathrm{CH}(\mathrm{Br}) \quad 7.47 \mathrm{e} 13 \quad 5.80$

+172 um $12.5 \% \mathrm{CH}(\mathrm{Br})$

Shot 33065 mimics the front end of shot 32499 - the 2 Mbar shot. Shot 33064

corresponds to an $875 \mathrm{kbar}$ shot. Shot 33062 corresponds to a $444 \mathrm{kbar}$ shot and shot 32495 corresponds to a 410 kbar shot. 


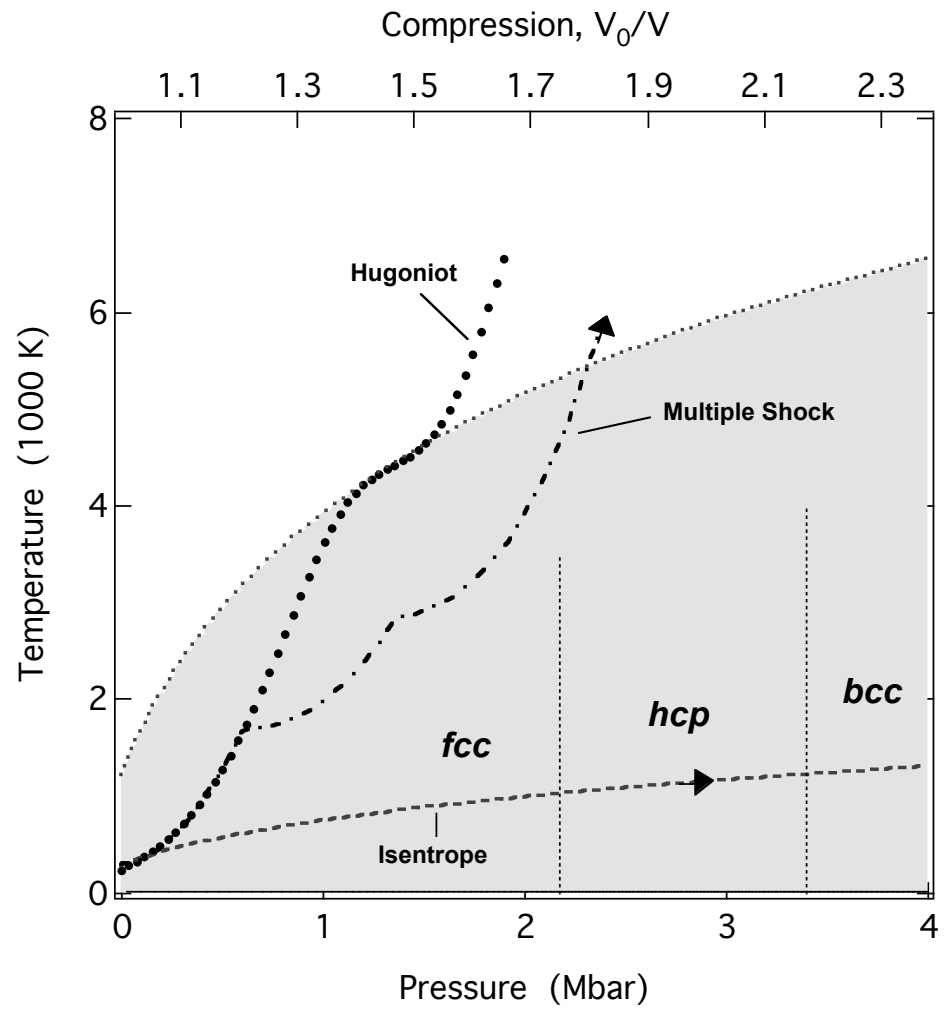

Figure 1_Lorenz_J.HEDP 


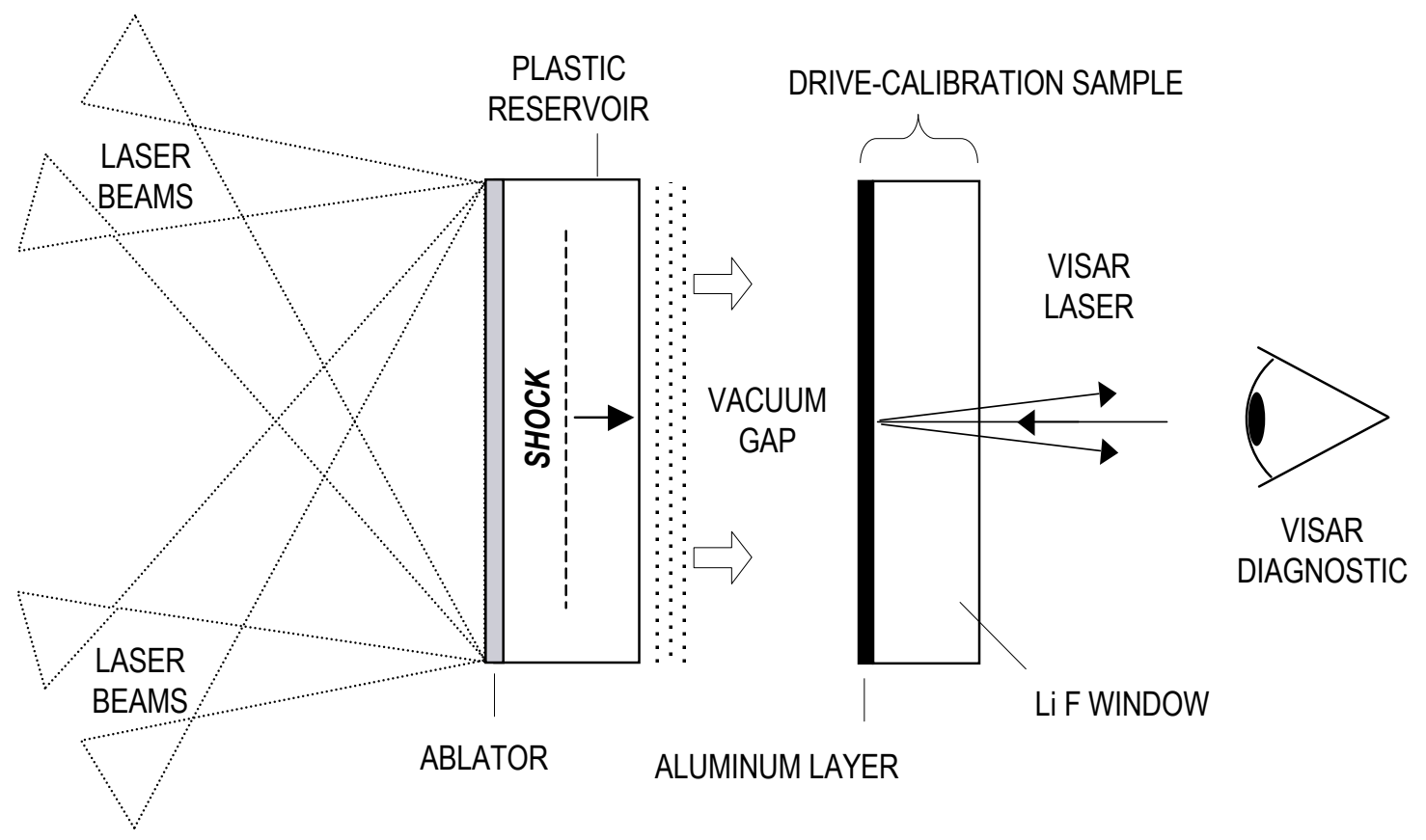

Figure 2_Lorenz_J.HEDP 
(a)

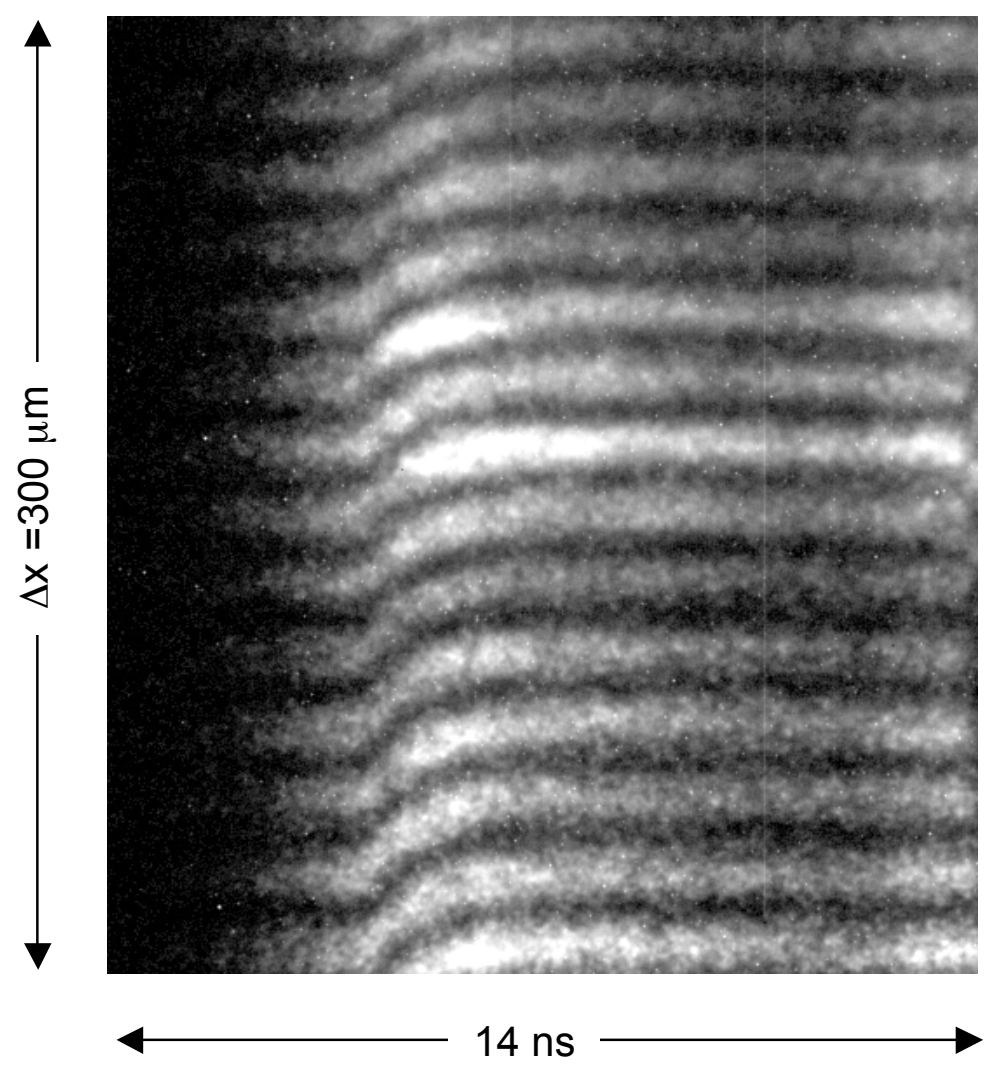

(b)

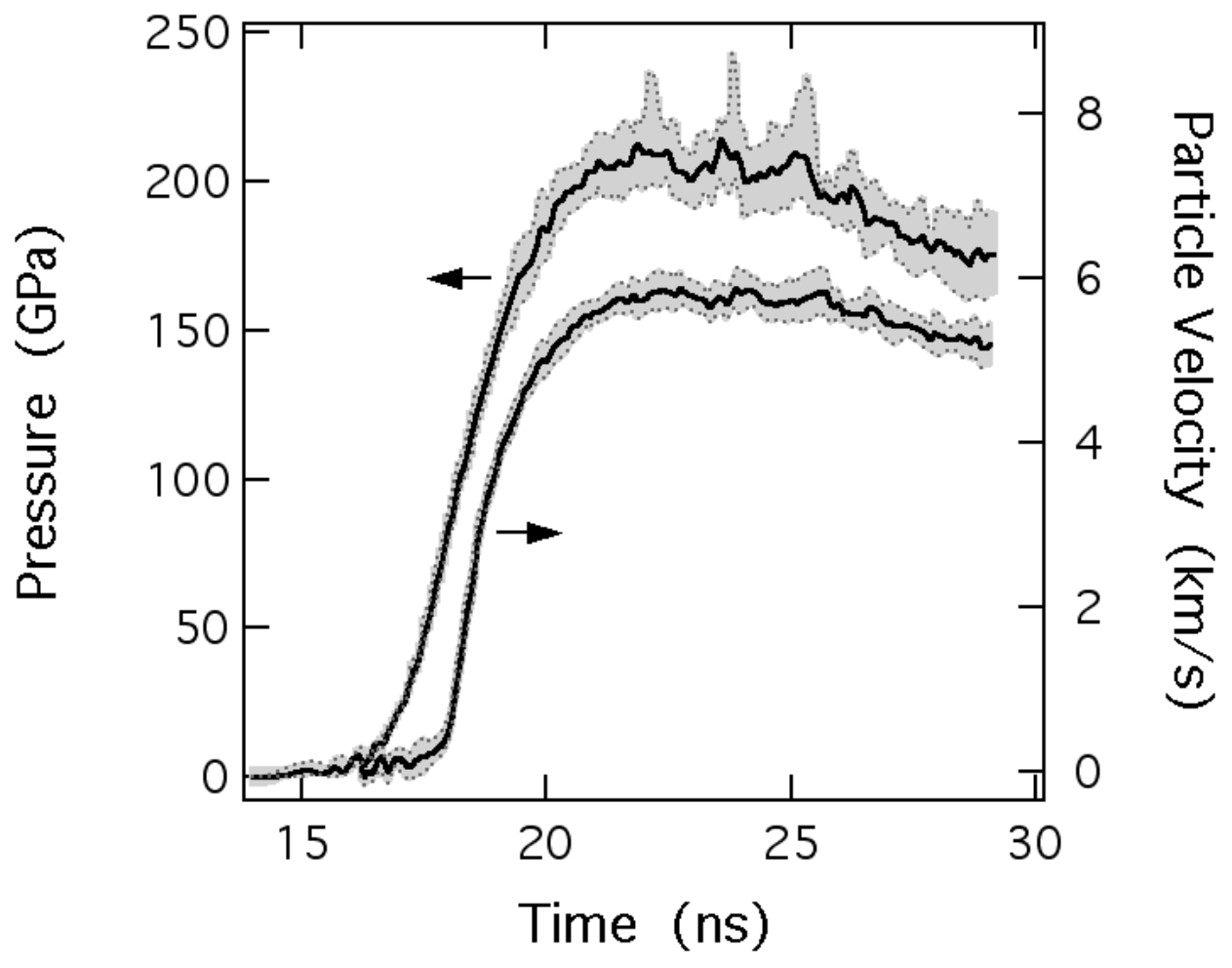

Figure 3_Lorenz_J.HEDP 


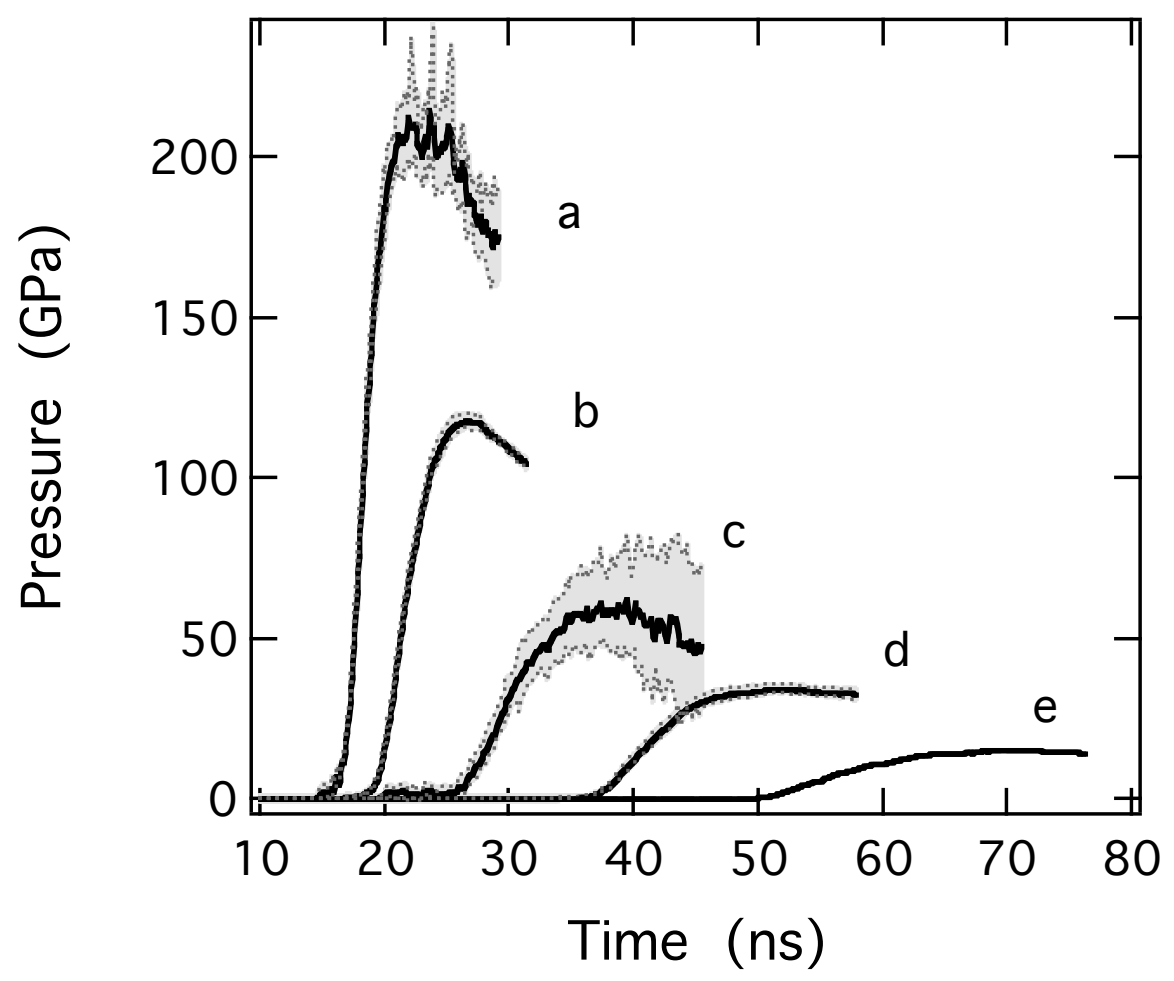

Figure 4_Lorenz_J.HEDP 


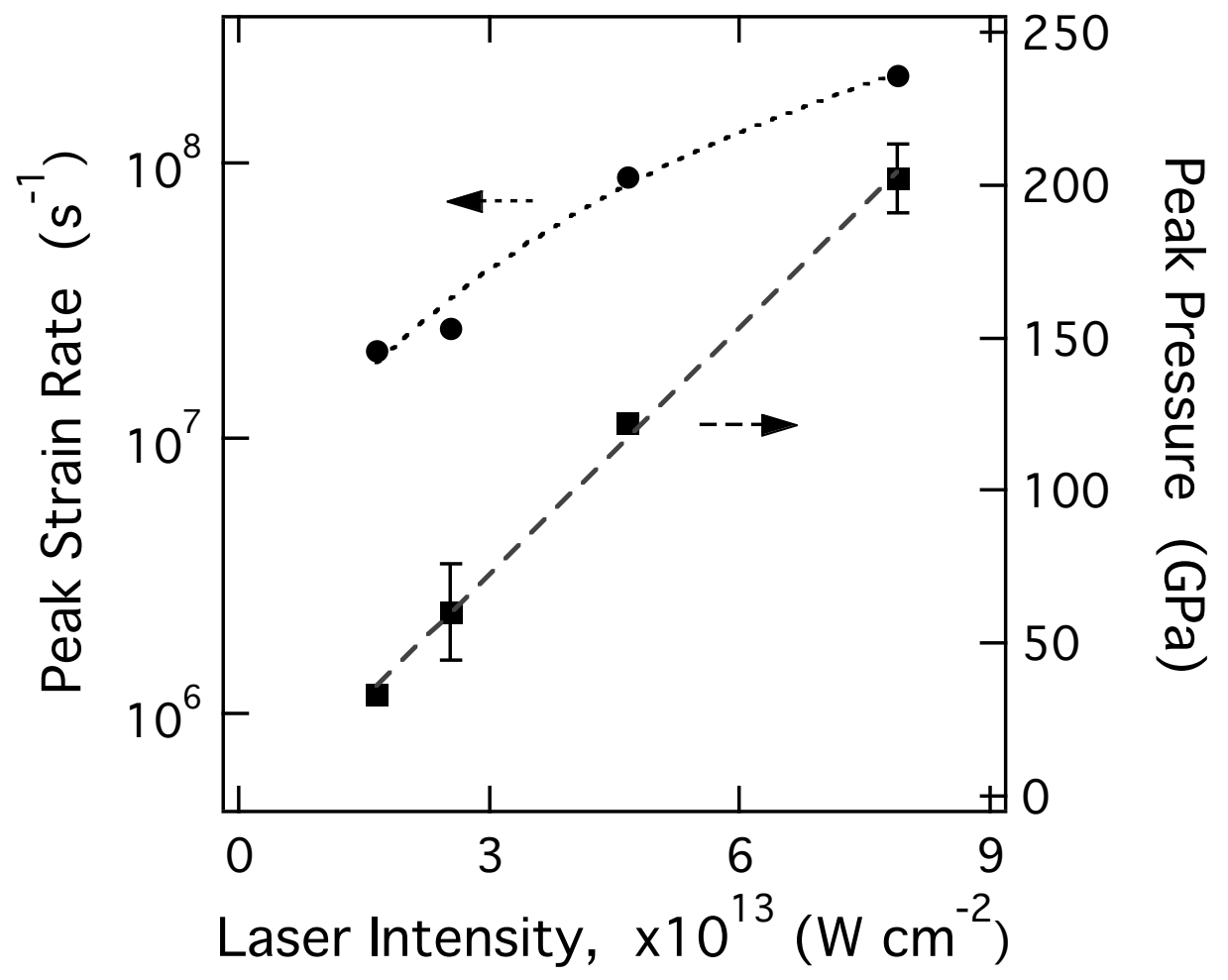

Figure 5_Lorenz_J.HEDP 

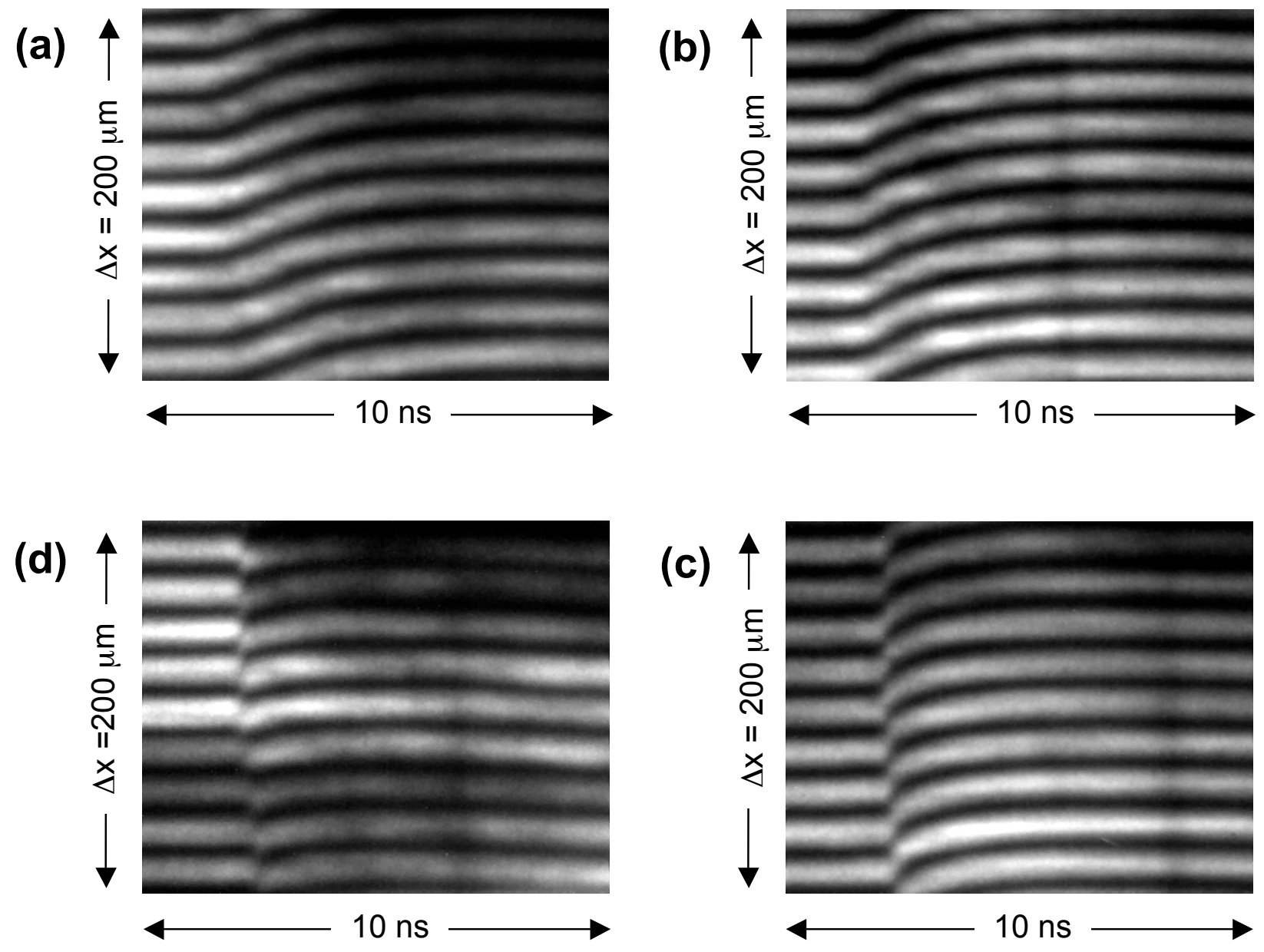

Figure 6_Lorenz_J.HEDP 
(a)

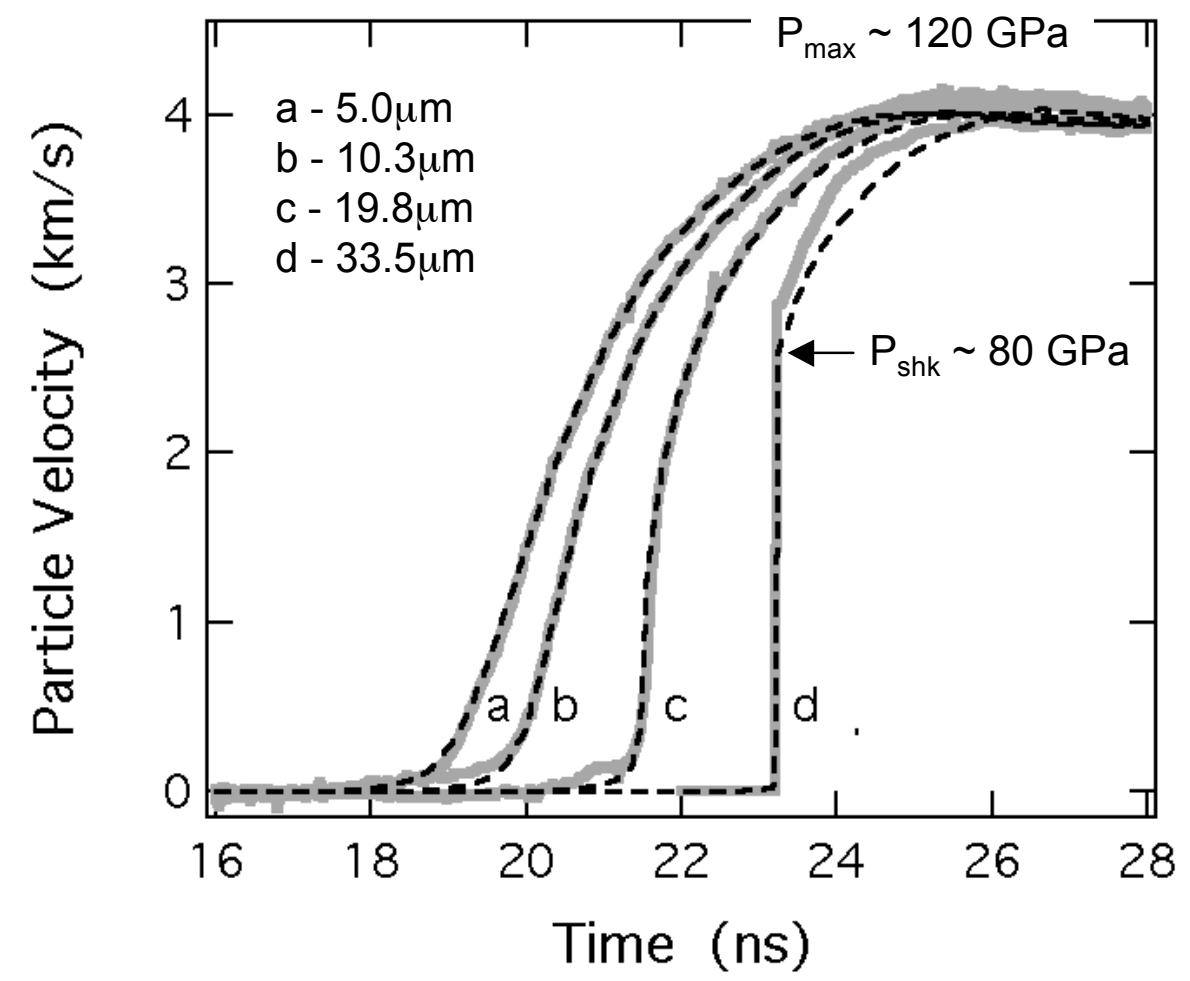

(b)

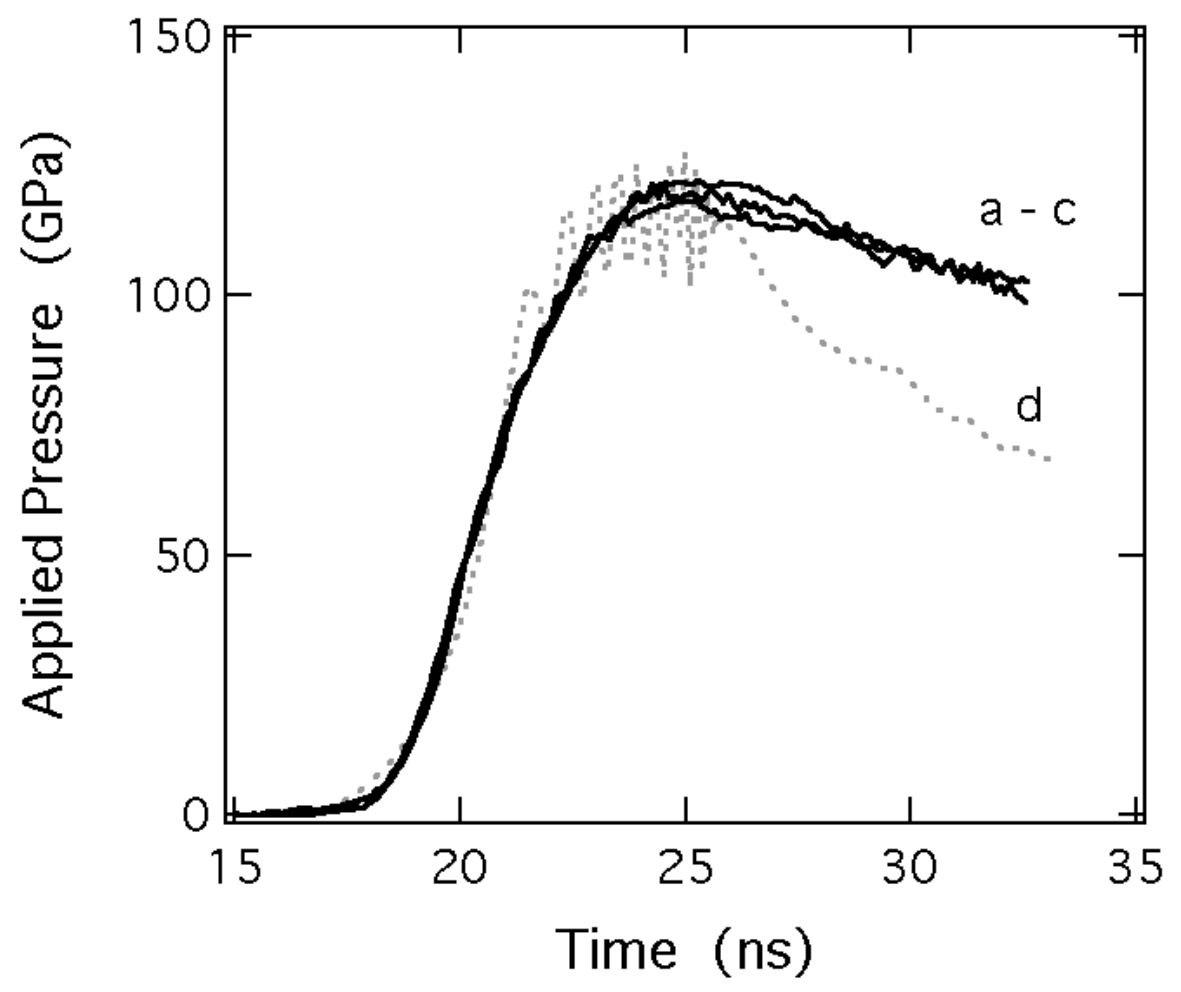

Figure 7_Lorenz_J.HEDP 


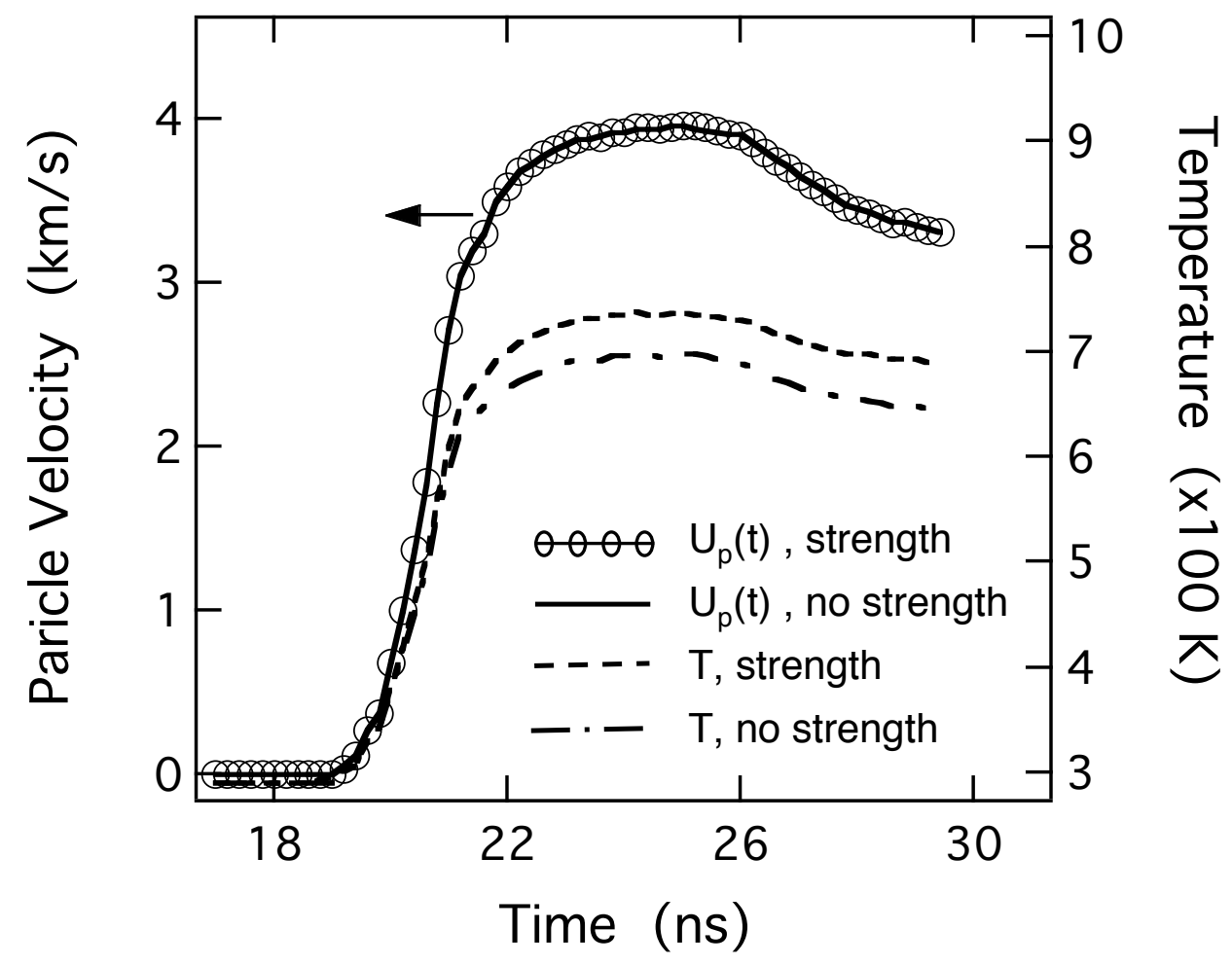

Figure 8_Lorenz_J.HEDP 
(a)

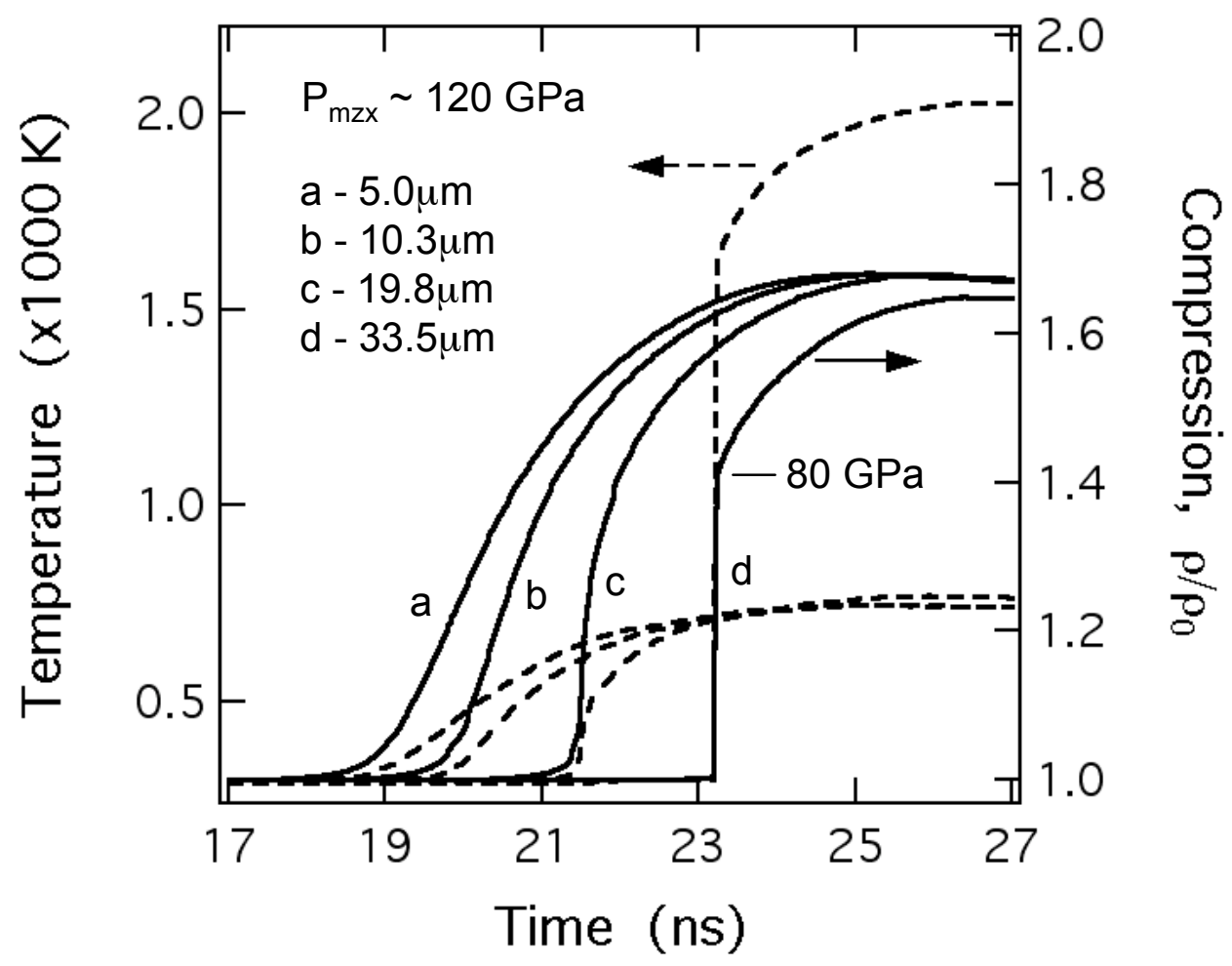

(b)

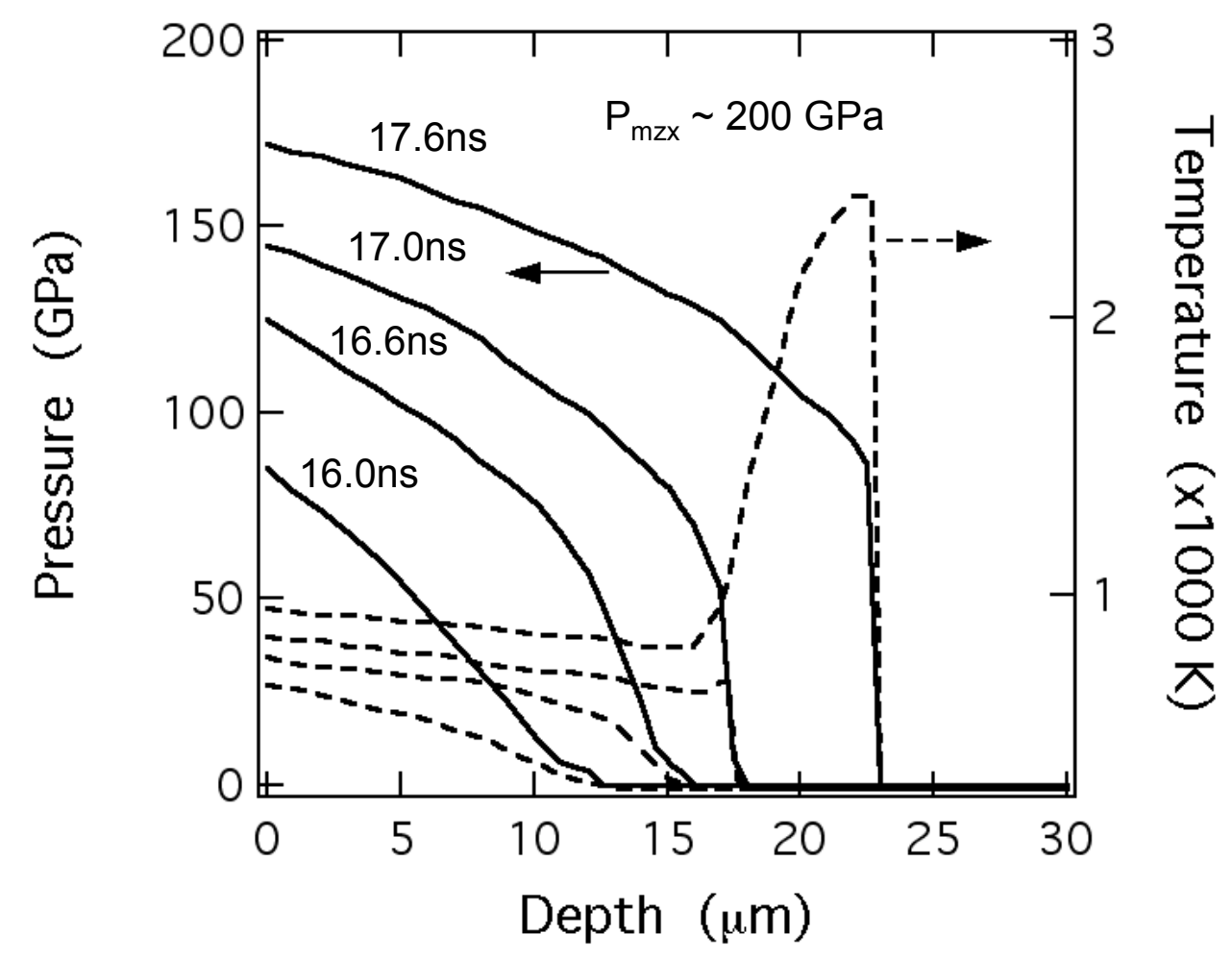

Figure 9_Lorenz_J.HEDP 


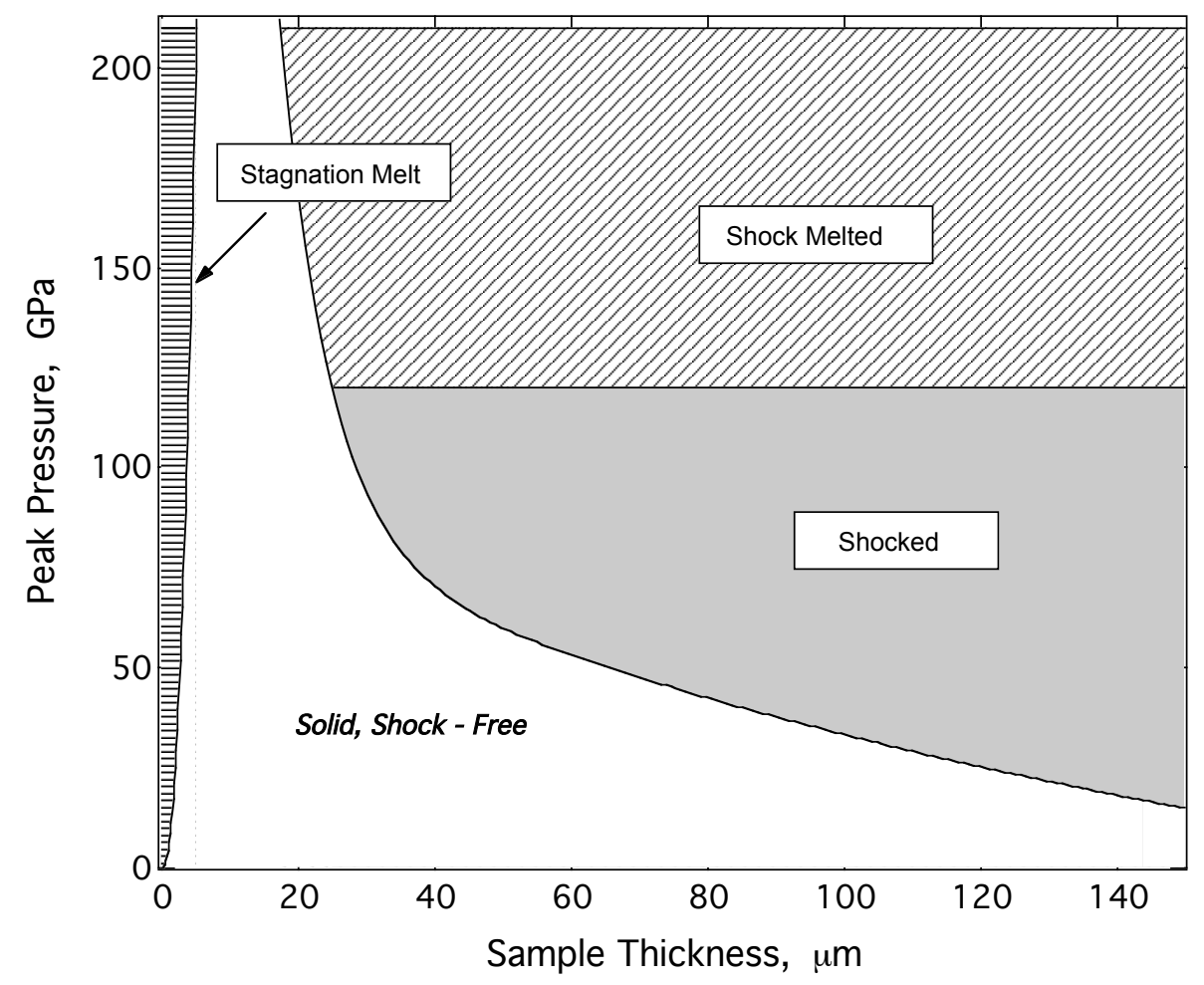

Figure 10_Lorenz_J.HEDP 